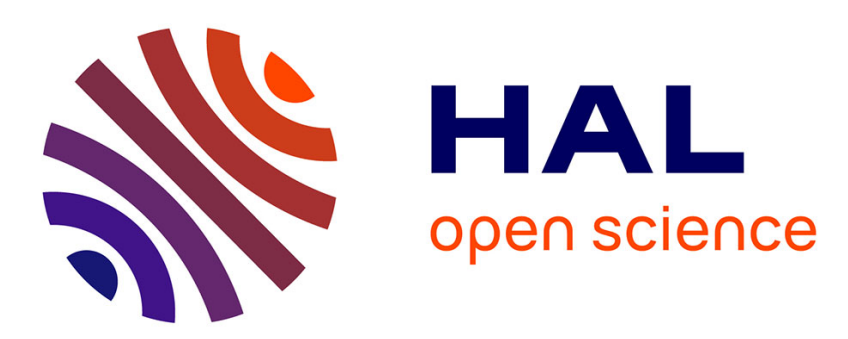

\title{
Evaluation of the DART 3D model in the thermal domain using satellite/airborne imagery and ground-based measurements
}

J.A. Sobrino, C. Mattar, Jean-Philippe Gastellu-Etchegorry, J.C. Jimenez-Munoz, Eloi Grau

\section{To cite this version:}

J.A. Sobrino, C. Mattar, Jean-Philippe Gastellu-Etchegorry, J.C. Jimenez-Munoz, Eloi Grau. Evaluation of the DART 3D model in the thermal domain using satellite/airborne imagery and ground-based measurements. International Journal of Remote Sensing, 2011, pp.1-25. 10.1080/01431161.2010.524672 . ird-00657976

\section{HAL Id: ird-00657976 \\ https://hal.ird.fr/ird-00657976}

Submitted on 10 Jan 2012

HAL is a multi-disciplinary open access archive for the deposit and dissemination of scientific research documents, whether they are published or not. The documents may come from teaching and research institutions in France or abroad, or from public or private research centers.
L'archive ouverte pluridisciplinaire HAL, est destinée au dépôt et à la diffusion de documents scientifiques de niveau recherche, publiés ou non, émanant des établissements d'enseignement et de recherche français ou étrangers, des laboratoires publics ou privés. 


\section{Evaluation of DART 3D model in the thermal domain using satellite/airborne imagery and ground-based measurements}

J. A. Sobrino*a ${ }^{* a}$ C. Mattar ${ }^{\mathrm{a}}$, J.C., J.P. Gastelllu-Etchegorry ${ }^{\mathrm{b}}$, Jiménez-Muñoz $^{\mathrm{a}}$, E. Grau ${ }^{\mathrm{b}}$

${ }^{a}$ Global Change Unit, Department of Thermodynamics, University of Valencia, c/ Dr. Moliner, 50 - 46100 Burjassot (Spain)

${ }^{\mathrm{b}}$ Centre d'Études Spatiales de la Biosphère (CESBIO), Université de Toulouse, Avenue Edouard Belin 18, 31401 Toulouse, France

*Corresponding author. Email: sobrino@uv.es

\section{Abstract}

This work provides an evaluation of the Discrete Anisotropy Radiative Transfer (DART) 3-dimensional model to assess the simulation of directional brightness temperatures both at-sensor and at-surface levels. Satellite imagery acquired with the Advanced Spaceborne Thermal Emission and Reflection Radiometer (ASTER), airborne imagery acquired with the Airborne Hyperspectral Scanner (AHS) sensor and ground-based measurements collected over an agricultural area were used to evaluate DART model at nadir views. Directional radiometric temperatures measured with a goniometric system at ground-level were also used to evaluate DART results at different view angles. DART model was evaluated over three different homogeneous plots: bare soil, green grass and sand. Results showed typically a good agreement between DART simulations and satellite, airborne and ground-based measurements, with Root Mean Square Errors (RMSE) below 2 K. However, three major discrepancies were found: i) differences higher than $4 \mathrm{~K}$ over bare soil when comparing DART and ASTER, attributed to turbulence-induced temperature fluctuations, ii) higher differences in at-sensor level comparisons than in at-surface level ones when using AHS, due to thermal heterogeneity of selected regions of interest in the image and also to differences in atmospheric correction performed over the imagery and the one included in the DART model, specially for bands located in lowest atmospheric transmissivity regions, and iii) RMSEs higher than $2 \mathrm{~K}$ when comparing DART results and groundmeasurement over the sand plot, due to the strong emissivity correction in 8-9 $\mu \mathrm{m}$ bands, where measured emissivity was below 0.75 . In despite of these discrepancies, this paper shows that DART model is a useful tool for simulating remotely sensed thermal images over different landscapes. New versions of DART model are continuously being released in order to solve technical problems and improving simulation results.

Keywords: DART, thermal infrared, temperature, emissivity, ASTER, AHS. 


\section{Introduction}

Land surface temperature (LST) is one of the most important variables related to energy fluxes at the earth's surface. Its physical magnitude is defined as the effective kinetic temperature of the earth surface "skin" (Pinheiro et al. 2004) and it is linked with the land surface emissivity (LSE), an intrinsic property of each land cover material. These variables influence the thermal infrared emission (TIR) of a given surface, which in turn, presents interactions with the atmospheric planetary boundary layer.

TIR can be measure by different techniques and is essential to retrieve the surface temperature. Indeed, the measured radiance is made of reflected and emitted radiative fluxes and is usually anisotropic, because all land surfaces have a special anisotropic behaviour in the optical and thermal-infrared domain. In this last spectral range, the directional or angular variation of emitted fluxes (described by the so-called brightness temperature) is determined by the distribution of surface temperature and emissivity between the elements such as canopy, structure of the vegetation or shadow and illuminated proportions (Balick et al., 1987; Kimes and Kirchner, 1983), as well as the amount of soil and vegetation observable by the sensor from a particular direction. All those parameters have been addressed in a number of models (see Menenti et al., 2008). Moreover, using in-situ measurements, the anisotropy condition has been addressed over several surfaces such as natural and crops (Lagouarde et al. 2000 and references therein), urban areas (Voogt and Oke, 1997, 1998) and semiarid covers (Chehbouni et al. 2001; McAtte et al. 2003).

A simple way to assess TIR and its respective angular behaviour is related with modeling and simulations process. Many physical and mathematical models have been developed to simulate the physical properties, like temperature or reflectance of a natural or urban surface. In the thermal infrared range, there are a wide variety of those models which combine optic-structural and thermodynamics parameters to simulate brightness temperature or other biophysical magnitude (Sobrino et al., 2005). They could be classified into four types: Geometrical Optical (GO); radiative transfer models (RT); hybrid models that combine geometrical-Optical (GO) and radiative transfer (RT) approaches and models derived from bidirectional reflectance distribution function (BRDF) kernel models (Yu et al. 2004). However, one of the most popular models that simulate thermal parameters (e.g. brightness temperature) with three-dimensional (3-D) structure arrange is the DART (Discrete Anisotropy Radiative Transfer) model.

DART model simulates radiative transfer in heterogeneous 3-D natural and urban scenes containing trees, shrubs, grass, soil, water fields, houses, etc. (GastelluEtchegorry et al. 1996). The model output predicts any specified directional sensor response between $0.3-30 \mu \mathrm{m}$ wavelengths. It has already been successfully tested for retrieving biophysical variables (Gastellu-Etchegorry and Trichon, 1998; GastelluEtchegorry et al. 1999; Guillevic and Gastellu-Etchegorry, 1999; Demarez et al. 2000, Gascon et al. 2004), using remotely sensed data. In addition, DART model continues to evolve with regular releases (www.cesbio.ups-tlse.fr/us/dart.htm), usually aimed to improve its accuracy, its potential for simulating optical remote sensing images and for inverting these images. This explains that it has been used (Demarez and GatelluEtchegorry, 2000; Gascon et al. 2001; Guillevic et al. 2003), alone or coupled with other models, in numerous successive versions with different improvement levels such as the introduction of digital elevation models. Here, we used the DART version 3.1.4 
which includes the simulation of atmosphere radiative transfer in the thermal infrared domain for simulating sensor brightness temperatures of natural and urban landscapes (Gastellu-Etchegorry et al. 2004). An illustrative scheme explaining the DART functioning model is presented in figure 1 .

The capability of DART in relation with other models has already been successfully tested in a number of works (Widlowski et al., 2007; 2008). However, these tests were mostly conducted in the visible and near infrared spectral domains. Thus, DART model deserves more analysis and comparisons in the thermal range, where few works addressed the useful of this Model (Guillevic et al., 2003; Gastellu et al., 2008; Sepulcre-Cantó et al 2009). In fact, the last work used DART model to describe irrigated areas over olive orchards using Advanced Spaceborne Thermal Emission and Reflection Radiometer (ASTER) and Airborne Hyperspectral Sensor (AHS) imagery, although in that work the brightness temperature was simulated without atmospheric contribution and only for a single spectral band in the thermal domain (10.0- 10.2 $\mu \mathrm{m})$.

One of the main scopes of DART-3D model is to simulate thermal remote sensing images using in-situ measurements as input. DART generates thermal images at-nadir and other view angles considering the atmospheric contribution, but this capability has not been widely evaluated. Therefore, the aim of this manuscript is to evaluate the angular brightness temperature simulated by DART model based on in-situ measurements and taking into account the atmospheric contribution. For this purpose, thermal imagery acquired over an agricultural area with five TIR bands of ASTER and ten TIR bands of the AHS images have been used. Additionally, angular brightness temperatures simulated with DART were evaluated using goniometric measurements.

In this work, data base from three intensive field campaigns carried out in the agricultural sector of Barrax (Spain) and in a sandiness area of Loobos beach (The Netherlands) have been used. They are the Spectra-Barrax campaign (SPARC 2004), the SENtinel-2 FLuorescence EXperiment (SEN2LEX 2005) and the Exploting the AnGular effects in Land surfacE observations from satellites (EAGLE, 2006). Both SPARC and SEN2FLEX were sponsored by the European Space Agency and EAGLE was sponsored by the European Union. All these projects addressed the ground acquisition data to calibrate future satellites missions, with a particular emphasis on multiangular remote sensing data. A complete description of SPARC and SEN2FLEX field campaigns appears in Sobrino et al $(2008 ; 2009 \mathrm{a})$ and a briefly description of EAGLE 2006 is detailed in Sobrino et al (2006). Finally, the present manuscript is organized as follows: section 2 presents methods and data set acquired in addition to the DART simulation. Section 3 presents the results of DART thermal simulations and comparisons with ASTER and AHS thermal imagery. Section 4 presents a discussion and section 5 shows the conclusion of this work.

\section{Data}

\subsection{Study area and field campaigns}

In the framework of its Earth Observation Envelope Programme (EOEP), the European Space Agency (ESA) carries out a number of ground-based and airborne campaigns to support geo/biophysical algorithms development, calibration/validation activities and simulation of future spaceborne Earth Observation (EO) missions. SPARC and SEN2FLEX field campaigns are samples of these field campaigns. Both of them were 
conducted in the Spanish agricultural area of Barrax, and they were carried out in an Spanish agricultural area (as described below) in 2004 and 2005. EAGLE campaign is another example of such a field activity, and it was carried out in 2006 in different natural sites in The Netherlands.

The study area of Barrax is located in La Mancha region, Spain. This test site is placed in the Western part of the province of Albacete, $28 \mathrm{~km}$ from the capital town of Albacete $\left(39^{\circ} 3^{\prime} \mathrm{N}, 2^{\circ} 60^{\prime} \mathrm{W}\right)$. The dominant cultivation pattern in the 10,000 ha area is approximately $65 \%$ dry land (two-thirds in winter cereals, one-third fallow) and $35 \%$ irrigated crops (75\% corn, $15 \%$ barley and 10\% others, including alfalfa) (Moreno et al. 2001). The climate of Barrax is of Mediterranean type, with heavy rainfalls in spring and autumn and dry in summer. It presents a high level of continentality, with quite sudden changes from cold months to warm months and high thermal oscillations in all seasons between the maximum and minimum daily temperatures. The rainfall statistics show that the mean annual rainfall is little more than $400 \mathrm{~mm}$ in most of the area (Moreno et al. 2001). The study area includes annual crops and natural surfaces like: alfalfa, wheat, oat, corn, green grass and bare soil. However, for this work two samples were selected concerning to green grass and bare soil site (Figure 2).

The Loobos site is located two kilometers south-west of the village Kootwijk, The Netherlands. In this are, continuous micrometeorological measurements are carried out since 1997 at a height of $23 \mathrm{~m}$ above the surface. In a radius of $500 \mathrm{~m} \mathrm{89 \%}$ of the vegetation consists of pine trees, with an average height of about 16 meter, $3.5 \%$ is open vegetation e.g. heather and the remainder is a mixture of coniferous and deciduous trees and boundary sectors of sand. Some more detailed information is available from the ALTERRA research web-site at: http://www.loobos.alterra.nl

\subsection{Instruments and Goniometric System}

The goniometric system consists in a metallic square base of $0.4 \times 0.4 \mathrm{~m}$ with a steel mast in the middle. This mast has $2.5 \mathrm{~m}$ height and it can move between -60 to $60^{\circ}$ with $10^{\circ}$ steps. At top of mast an extensible metallic arm is located to support any physical instrument. The goniometric system can be used to measure in one plane once time because it does not have azimuthal moves. However, the low weight (approx. $10 \mathrm{Kg}$ ) and its simple moving conditioned this goniometric system to facilitate the measures and the transport between different targets.

To measure the surface temperature, a thermal radiometer was mounted in the goniometric system. The thermal radiometer was a CIMEL CE 312-2 which contains five narrow bands such as: $8.1-8.5 ; 8.5-8.9 ; 8.9-9.3 ; 10.3-11.0 ; 11.0-11.7 \mu \mathrm{m}$, and one broad in the spectral region between 8 and $13 \mu \mathrm{m}$. This radiometer has $8^{\circ}$ of field of view and accuracy equal to $0.01 \mathrm{~K}$, more details of this radiometer are well described in Jiménez-Muñoz and Sobrino (2006). This thermal radiometer was also used for transects measurements. Finally, a diffuse reflectance standard plate (Infragold, Labsphere Inc.) has been utilized to measure the sky irradiance.

\subsection{Ground Data Acquisition during SPARC 2004}

The SPARC field campaign started in July 2003, but the main data collection was carried out in July 2004. It was organized under the framework of different activities 
related to the Surface Processes and Ecosystem Changes Through Response Analysis (SPECTRA), an ESA candidate Core Earth Explorer mission selected for phase-A studies but finally rejected for phase-B. Ground-based measurements included vegetation, atmospheric and radiometric parameters, among others. Different satellite and airborne imagery were also collected during the campaign. Detailed information can be found in Moreno et al. (2004).

In this work, we used several in-situ measurements carried out on July $18^{\text {th }} 2004$. They are thermal, structural and atmospheric measurements. Thermal measurements were performed over bare soil (BS) and green grass (GG) test sites. They consisted in a linear transect retrieving several point temperature measures. This was carried out using a CIMEL CE 312-2 thermal radiometer. The sky irradiance was measured using the infragold plate at the beginning and the end of transects. In order to obtain the LST, an essential parameter for DART thermal simulations, the Temperature and Emissivity Separation (TES) method has been applied. This method utilizes a "calibration curve" to recover the surface emissivity (Kealy and Hook, 1993; Gillespie et al., 1998) and it was originally developed to generate ASTER - TES standard products, but Payan and Royer (2004) suggested its application to ground-based measurements. LSE is a surrogate variable which is linked with LST and it is also needed in DART simulations. Here, the GG spectra from the ASTER spectral library (Baldridge et al., 2009) have been used. Meanwhile for BS, we used the emissivity spectra for the Barrax soil described in Sobrino et al (2009b).

Angular thermal measurements have also been carried out in SPARC 2004. The Goniometric measurements were performed over the same natural plots mentioned below (GG and BS surfaces). Those measurements start on $21^{\text {th }}$ July 2004 at daytime, between 10:00 and 10:30 UTC, generating two series of angular brightness temperature between $-60^{\circ}$ and $60^{\circ}$, with $10^{\circ}$ steps. For nighttime, the measure plan was similar than daytime, although measurements start at 00:10 and finish at 01:00 UTC. For each angular series, the sky irradiance was measured before and after the measurements using the infragold plate. During SPCAR 2004, good weather conditions such as calm winds and clear sky accompanied all ground thermal measurements at day and nighttime. Finally, the goniometric system and the samples measured during SPARC 2004 field campaign are shown in figure 3a,b.

Vegetation structural measurements were carried out over GG cover. They consist in height crop and the Leaf Area Index (LAI) measurements, which values were retrieved following the methodology described by Martínez et al (2009). The LAI and height values were $0.5 \pm 0.2$ and $0.3 \pm 0.1 \mathrm{~m}$ respectively. The Leaf Area Distribution (LAD) is another important parameter to characterize vegetation covers and important to characterize vegetation crops, this parameter is required by DART model to simulate any vegetation surface. However, here we assumed the LAD type equal to spherical, because its variable describes the orientation of the leaves within the canopy and is not be easily assessed, so environmental studies assume a spherical angles distribution (Ross, 1981).

As regards to atmospheric measurements, Gascon et al. (2001) greatly improved DART coupling an atmospheric radiative module that simulates remote sensing images at different altitudes. In fact, DART model simulates radiance at any altitude include the radiance emitted by land surfaces, the radiance reflected by the Earth surface and the 
atmospheric radiance. However, this approach was validated in visible and short infrared range and partially tested for thermal infrared domain (Gastellu-Etchegorry, 2008). Hence, one of the main scopes of this work is to simulate the brightness temperature considering the in-situ atmospheric contribution. Therefore, an atmospheric vertical profile was derived from a Vaisala RS-80 radiosonde launched on 18th July 2004 at 11:00 UTC over the study area. It provides the atmospheric thermodynamic conditions between the near land surface to middle stratosphere $(\sim 25 \mathrm{~km}$ altitude). This profile was completed with the midlatitude summer atmosphere Modtran model (Berk et al., 1999) and included in DART atmosphere database.

\subsection{Ground Data Acquisition during SEN2FLEX 2005}

The interest of SEN2FLEX field campaign was focused on thermal measurements and AHS data analysis to demonstrate the use of TIR remote sensing for different environmental applications. In particular, to retrieve thermal parameters such as LST, LSE and heat fluxes like evapotranspiration (ET), which provides useful information for water irrigation management.

AHS technology (developed by SensyTech Inc., currently ArgonST, USA) is operated by the Spanish Institute of Aeronautics (INTA) and it was placed onboard the aircraft CASA 212-200 Paternina. The AHS sensor is based on the integration of many advanced technologies developed by SensyTech under R\&D contracts over the past few years. While the combination of these components is offered here for the first time, each of the individual items has been delivered and field-tested in operational use. The AHS incorporates advanced components to ensure high performance while maintaining the ruggedness to provide operational reliability in a survey aircraft. The main AHS technical specifications and the arrangement of the spectral bands are 80 from the visible to the thermal range; FOV: $90^{\circ}\left( \pm 45^{\circ}\right)$, IFOV: $2.5 \mathrm{mrad}$, GFOV: $2-6 \mathrm{~m}$ at $140 \mathrm{kt}$ cruise speed; scan speed: $6.25,12.5,18.75,25,31.25,35 \mathrm{rps} ; 12$ bits digitised; 750 samples per line; black body thermal references (set to $15^{\circ} \mathrm{C}$ and $55^{\circ} \mathrm{C}$ ). The arrangement of the AHS thermal bands from 71 to 80 is given in Table 1.

SEN2FLEX field campaign has two periods where an intensive field campaign was carried out. They are for June and July 2005, although the main data acquisition was in July. In this work, ground data acquisitioned on $12^{\text {th }}$ July 2005 have been used. As in SPARC field campaign, several ground thermal measurements in addition to vegetation structural parameters and atmospheric profiles have been carried. In order to retrieve the LST and LSE, here we used the LST from the AHS images, which thermal procedure is explained in the next section. The LSE was considered similarly to the previous section. Moreover, vegetation structural parameters for GG were height and LAI with values equal to $0.6 \pm 0.3 \mathrm{~m}$ and $1.1 \pm 0.1$ respectively. LAI was calculated following the method proposed by Martínez et al (2009). LAD was assumed spherical and in order to obtain the atmospheric profile, a Vaisala RS-80 radiosonde was launched at 10:48 UTC over the central coordinates in the test area (39 $3^{\circ} 44^{\prime \prime} \mathrm{N} ; 2^{\circ} 6^{\prime} 10^{\prime}$ ' W). This profile was used to consider the atmospheric effect and correct the AHS images for retrieving the land leaving radiance at surface level. This method was detailed in the section 3.1. Additionally, this vertical profile was used to simulate thermal images in DART as mentioned in the above section.

\subsection{Ground Data Acquisition during EAGLE 2006}


EAGLE field campaign presented a different weather situation than the both above described, because atmospheric instability in addition to persistent winds, gust and frequently clouds could affect the measure plan. For this reason, the sand dunes sample (NS) of Loobs, The Netherlands was collected in a special device and transported for after outdoor measures. NS sample was collocated on a plate $(30 \times 60 \times 10 \mathrm{~cm})$ in the roof of the Image Processing Laboratory - University of Valencia with calm winds and clear sky conditions. As in the SPARC campaign angular measurements were performed with the CIMEL CE 312-2 thermal radiometer at midday. Three angular brightness temperature series have been carried out accompanied with sky irradiance measurements using the infragold plate. Other similar laboratory experiences are well described in Sobrino and Cuenca (1999) and Cuenca and Sobrino (2004) which addressed the angular thermal behaviour over other natural surfaces. Finally, the goniometric system and NS sample are shown in figure $3 \mathrm{c}$.

\section{Methods}

\subsection{Thermal Image processing}

ASTER products for SPARC field campaign were acquired at 11:00 UTC on July $18^{\text {th }}$ 2004. These products were the radiance at the Top Of Atmosphere or sensor (TOA) without atmospheric corrections (Level-1B) and the land leaving radiance (AST-09T or Level - 2) which can be considered as Bottom Of Atmosphere (BOA). From these products, the brightness temperature was calculated using the inversion of Planck law. Therefore, the so-called brightness temperature derived from ASTER data at levels 2 and 1-B was used to be compared with DART simulated brightness temperature. In order to carry out this test, two pixels of ASTER images (Level - 1B and Level - 2) were selected, both for BS and GG respectively, and the comparison were performed for each ASTER thermal band. A full description of the ASTER sensor and their standard products is given in Abrams (2000).

During SEN2FLEX field campaign, AHS thermal imagery was acquired for $12^{\text {th }}$ July 2005. It was composed by AHS images at 2,067 m above ground level, with $3 \mathrm{~m}$ of pixel size. Radiosonde data, launched at the same time of the flight overpass was used to calculate atmospheric thermodynamics parameters useful for correcting thermal images. They are the atmospheric transmissivity $(\tau)$ and the upwelling $\left({ }^{\uparrow} L\right)$. For which, MODTRAN 4.0 radiative transference code (Berk et al., 1999) has been used. Those thermodynamics parameters were used in the following radiative transference equation to obtain the land leaving radiance at surface level.

$$
L_{i}^{L L R}=\frac{L_{i}\left(T_{i}\right)-L_{i}^{\uparrow}}{\tau_{i}}
$$

Where $L_{i}^{L L R}$ is the land leaving radiance, $L_{i}\left(T_{i}\right)$ is the radiance at sensor level and $i$ belongs to each AHS thermal band. To retrieve the brightness temperature at sensor and surface level the inversion of Plack's law was applied to $L_{i}^{L L R}$ and $L_{i}\left(T_{i}\right)$. Finally, a split-window method was used to obtain the LST values from AHS images. This method is well described in Sobrino et al. (2006).

\subsection{Remote images simulated with DART model in the thermal domain}


DART model can operate combining the ray tracing and the discrete ordinate methods. It was designed to simulate the reflectance or temperature of different landscapes using a 3D matrix of cells equivalent a turbid media in the case of vegetation or air, and opaque media in the case of ground, trunks or urban elements. Here, DART model was used to simulate the brightness temperature of a natural scene like BS, GG and NS covers.

DART has many modes to simulate thermal images, two of them are the lambertian and specular monospectral (MO) and the lambertian and specular multispectral (MS) modes. The main difference between those models is the way to calculate the effective emissivity for the desired range, because in MO mode users need to input the effective central emissivity value and in MS, DART estimate the emissivity based on spectra data. Additionally, other difference concern to the thermal mode related with the scene illumination, where MS used a combination between thermal with reflectance of sun radiation, whereas MO uses the thermal radiation, more details of these modes appear in Gastellu-Etchegorry (2007).

The temperature simulated by DART was obtained in MS for different thermal bands related with ASTER and AHS. Therefore, two modelling study were performed, one belongs to compare DART with ASTER products and the other one to compare DART with AHS imagery. For the comparison, at nadir simulated images in DART were used.

For DART and ASTER comparison, a thematic scene comparable to ASTER pixel was simulated in DART. It consisted in a landscape of $90 \times 90 \mathrm{~m}$ similar than an ASTER pixel. This scene was used to simulate BS and GG covers separately. Owing to the simulation of BS (as an opaque media) and GG (turbid media) have different ways to compute the radiative transfer, so the cell size for BS and GG were $3 \times 3 \times 0.1 \mathrm{~m}$ and $3 \times$ $3 \times 0.5 \mathrm{~m}$ respectively, the height of the last one is according to the crop height measured in-situ. After that, each simulation was programmed for the five thermal spectral bands of ASTER, as a result five thermal simulated images at Bottom of the Atmosphere (BOA) and Top of The Atmosphere (TOA) were created. Thermal parameter (LST and spectral emissivity), structural and atmospheric parameters achieved during SPARC field campaign were included in DART and are presented in table 2 .

In relation to AHS simulation, a scene of $60 \times 60 \mathrm{~m}$ has been constructed in DART (equivalent a square of $20 \times 20$ AHS pixels). The scene size considered a homogenous zone in where the GG and BS were located. The cell size in DART was $3 \times 3 \times 0.1 \mathrm{~m}$ and $3 \times 3 \times 0.5 \mathrm{~m}$ for BS and GG respectively. The thermal bands of AHS were considered in DART simulation, so ten images at BOA and at-sensor level have been generated. The sensor level is about $2.000 \mathrm{~m}$ over ground and this altitude was input in DART model. Finally, thermal, structural and atmospheric parameters achieved during SEN2FLEX field campaign were included in DART. They are presented in table 3.

\subsection{DART and Thermal imagery comparison.}

DART model can simulate the brightness temperature of a given landscape at three different atmospheric levels, at surface, middle and top of atmosphere (altitude equivalent to $84 \mathrm{Km}$ ). In case of ASTER thermal images simulated by DART, we 
considered the simulated brightness temperature at surface to compare with ASTER level-2 pixel, selecting the temperature of an ASTER pixel, for BS and GG, and directly compared with the value simulated by DART. The same comparison criteria was used to the temperature simulated by DART at $84 \mathrm{Km}$ with ASTER level-1B values. These comparison, at BOA and TOA were carried out for the five thermal bands. On the other hand, in the case of the brightness temperature simulated by DART on the 10 thermal bands of AHS, two levels were generated, at surface and sensor level. Since, the area selected in AHS was a square about $20 \times 20$ pixels, the average of them was used to compare with average value retrieved by DART of the whole simulated scene. This was carried out for each thermal band and for BS and GG cover.

Finally, as a measure of agreement, we used the root mean square error (RMSE) to evaluate results and a sensibility analysis of DART, ranging LAI magnitudes and LAD types were carried out. This sensibility analysis has relation with the influences of vegetation structural parameters over the radiative transfer simulation and how they affect the comparison with remotely sensed data. Because DART model simulates vegetation cover as the juxtaposition of turbid leaf cells that are characterized by their leaf volume density, their leaf angle distribution (LAD) and their optical properties (Duthoit et al. 2008). Therefore, vegetation structural and optical variables influence strongly the reflectance and brightness temperature of earth surfaces. First the LAI were ranging for $0.5,1.0,1.5,2.0,2.5,3.0$ and 5.0, while ellipsoidal, uniform, extremophile, vertical and plagiophile LAD types were simulated. Finally, the cell sizes varying the $\Delta \mathrm{x}$ and $\Delta \mathrm{y}$ for 1.0, 2.0, 3.0, 5.0, 10, 50 and 90 for ASTER and 1.0, 2.0, 3.0, 5.0, 10, 60 for AHS were also simulated

\subsection{Angular temperature simulated with DART model and goniometric comparison}

The DART model (v.3.1.4) has been used here to simulate the angular brightness temperature of the three natural surfaces by comparing with in-situ measurements. The average brightness temperature for BS, GG and NS samples were simulated for the five narrow bands matched with the CIMEL CE 312-2 thermal radiometer. To construct a natural scene similar to the field, we designed a $10 \times 10 \mathrm{~m}$ scene in DART, which will be assigned to BS, NS or GG cover. The cell size was the defect value $0.5 \times 0.5 \times 0.5 \mathrm{~m}$, but further sensibility analysis of the cell size has been performed. A previously work, used the MO mode to simulate a row crop and compared their results with in-situ measurements (Guillevic et al., 2003). In this work, we used both modes, MO and MS to compare these results with angular measurements. Finally, the input data for angular simulation is summarized in table 4.

\section{Results}

\subsection{ASTER and DART brightness temperature comparison}

The comparison at ground level between DART and ASTER Level 1-B presents an important discrepancy which can be evidenced for bare soil cover (figure 4a), where the RMSE higher than $4 \mathrm{~K}$. This discrepancy can be attributed to natural spatial heterogeneity and temporal variability of temperatures on the ground (the so-called "snapshot effect"), especially pronounced for bare soil as opposed to green vegetation, and leading to unrepresentative comparisons that may be off by several K. In fact, for green grass a better agreement was obtained, since the RMSE is lower than $0.5 \mathrm{~K}$. In 
Sobrino et al. (2007), the "snapshot effect" is widely analyzed over agricultural areas using ASTER imagery.

Comparisons were also done for TOA level (figure 4b) using ASTER Level-2 product and DART simulations. In this case, GG cover presents the minimum RMSE value $(0.55 \mathrm{~K})$ and maximal RMSE occurs with bare soil cover, again due to the "snapshot effect". The RMSE for each thermal band at Level-1B is lower than Level-2. Moreover, on the whole set of comparison, the brightness temperature simulated by DART, presents for BS an overestimation about $4 \mathrm{~K}$ in comparison with ASTER products. Similar case is presented in GG cover, although the overestimation is lower than $1 \mathrm{~K}$. In general, similar best agreements were obtained between DART and ASTER products for green grass cover, which presents the lower RMSE (Table 5). The comparison errors for DART and ASTER products on GG were - $0.19 \pm 0.42 \mathrm{~K}$, lower than the obtained for BS comparison which is $-4.3 \pm 0.67 \mathrm{~K}$.

\subsection{AHS and DART brightness temperature comparison}

For BS, the comparison at surface level between DART and AHS imagery, presents a good agreement in the whole set of AHS thermal bands. The RMSE is equal to $0.63 \mathrm{~K}$ (figure 5a), while the comparison at sensor level (figure 5b) is slightly different. Because some differences about $4 \mathrm{~K}$ are presented at extreme bands (band 71 and 80) and lower differences between 1 and $2 \mathrm{~K}$ over bands 72 and 79. The RMSE for this comparison is $2.3 \mathrm{~K}$ but if we consider the RMSE over band 72 to 78 the RMSE decrease to $1.1 \mathrm{~K}$. For the case of $\mathrm{GG}$, a similar situation was presented. The comparison between DART and AHS at-surface level present a RMSE close to $0.5 \mathrm{~K}$ and its increase to $1.36 \mathrm{~K}$ for at-sensor comparison. For GG, the errors between AHS and DART increase at extreme bands, for example, differences higher than $2 \mathrm{~K}$ for bands 71 and 80. This difference can be appreciated in other works (Sobrino et al., 2006), since the extreme bands like 71 and 80 have the central effective wavelength in atmospheric bands absorption, like water vapour (for band 71) and carbon dioxide (for band 80). The adjacent bands such as 72 and 79 are affected for the atmospheric absorption, although the differences are minor. Another absorption band is presented in AHS sensor, the band 73 is in the middle of the ozone gas absorption and although at flight altitude $(\sim 2,000)$ ozone absorption is minimal. Finally, DART overestimate the brightness temperature and present higher values than AHS for BS and GG at-sensor level. At surface level the brightness temperature simulated by DART does not present a clear over or underestimation.

\subsection{DART and angular measurements}

The brightness temperature simulated by DART for BS and GG do not present a strong angular influence before $30^{\circ}$ and also registered on goniometric measurements which show an angular difference higher than $2 \mathrm{~K}$. Figure 6 and 7 present the angular comparisons at day and nighttime for BS and GG respectively. This low anisotropy could be explained for the surface cover, because BS is a minimum roughness barren area and GG has low values of height and LAI. Other works carried out over natural surfaces present important differences between angular and nadir temperatures (Lagouarde et al., 1995; Li et al., 2004). However, it is important to take into account that the humidity, shadows and fraction vegetation proportion, in addition to measure protocol may perhaps affect the angular temperature measured in-situ. This reveals the 
influence of the cell type used here, because turbid or GG and opaque for BS present different ways to estimate the leaving radiance of each cell and therefore the brightness temperature. In addition, the influences of the DART mode, mono or multispectral, can be evidenced on the first three thermal bands $(8.1-9.3 \mu \mathrm{m})$, in where the emissivity spectra increased a $4 \%$ approximately in this range. This should be attributed to the effective emissivity values, which are useful for the thermal monospectral simulation and were calculated used a convolution between the spectra and the CIMEL CE 312-2 filter function in the case of MO. Although, for MS mode, DART calculates the emissivity using a weighted average between the desired thermal domain and spectra used in the simulation.

On the other hand, the bias and RMSE between the brightness temperature simulated by DART and angular in-situ measurements (Table 6) are, in average, less than $1 \mathrm{~K}$ for daytime, and for nighttime the thermal range $8.1-8.5 \mu \mathrm{m}$, evidences a bias higher than $1 \mathrm{~K}$, specially for BS. The thermal range located after the $10.2 \mu \mathrm{m}$ presents minor differences for day and nighttime. The RMSE are lower for BS than GG at daytime, whereas for nighttime there is an opposite case, because the RMSE for BS present higher values than GG. DART model does not have a special mode to simulate at nighttime, however, we configured the sun position at nadir and included the LST retrieved at nighttime as the input thermal parameter. In our case, the simulated scene is homogeneous and does not have gap fractions or row crops (i.e. shadow proportions), because in that configurations the sun-shadow-temperature relationship is strongly observed (Guillevic et al., 2003).

For NS sample, the differences between simulation and measurements is noticeable for the thermal range between $8.1-8.9 \mu \mathrm{m}$ (Figure 8 ). This difference could be attributed to the emissivity values calculated for the simulation. NS sample, as a sand type, has a high content of quartz. This component present a special behaviour between 8.0 and $10.0 \mu \mathrm{m}$ where exist the Reststrhalen bands, and emissivity magnitudes varying with the size sample (Moersch and Christensen, 1995). In fact, the amplitude emissivity for our sample is high because at $8.1-8.5 \mu \mathrm{m}$ was $17.6 \pm 5.8 \%$ and for $8.5-8.9 \mu \mathrm{m}$ was $9.8 \pm$ $3.0 \%$. This strong variation on the emissivity magnitudes explain the differences retrieved by $\mathrm{MO}$ and MS simulations, obtaining 2 to $4 \mathrm{~K}$ for those two critical spectral range (Table 6). The rest of thermal simulated bands present little differences between MO and MS simulations, although in average the difference between DART simulations and in-situ goniometric measurements ranging between 1 and $2 \mathrm{~K}$. For simulation modes, mono and multi spectral, the highest RMSE are presented in $8.1-$ $8.5 \mu \mathrm{m}$ with $3.0 \pm 0.3 \mathrm{~K}$ and $6.7 \pm 4.9 \mathrm{~K}$ respectively. This was explained by the arguments mentioned before.

\subsection{DART sensitivity results for AHS and ASTER}

Figure 9 a,b shows the LAI influences for ASTER at BOA and TOA levels respectively. For BOA level a high difference is observed when LAI values are higher than 3.0. For band $10(8.1-8.5 \mu \mathrm{m})$ and band $12(10.3-11.0 \mu \mathrm{m})$ the differences are minimal. The second level show similar behaviour, LAI values higher than 3.0 present strong differences over all for bands $12(8.9-9.3 \mu \mathrm{m})$ and band $13(10.3-11.0 \mu \mathrm{m})$. Despite those differences LAI magnitudes between 0.5 and 2.0 did not present a high influences in the brightness temperature comparisons. There is important to take into account that LAI magnitude is an essential variable to simulate vegetation cover over the thermal 
domain with DART model. Here, the brightness temperature simulated by DART depends on LAI value which will be in concordance with the cell size. For the LAI sensibility analysis, the cell size used here (table 2) was proportional to LAI values under 3.

On the other hand, figure 10 a,b shows the LAI influences for AHS at surface and sensor levels respectively. A high difference is observed at band $73(8.9-9.4 \mu \mathrm{m})$ at both levels. As in ASTER comparisons, for LAI values higher than 3 the differences are considerable. The atmospheric contribution is evidenced for bands 71, 79 and 80 which retrieved differences of $2 \mathrm{~K}$ and above. At surface level LAI values ranging between 0.5 to 2.0 present differences lower than $1 \mathrm{~K}$ and after band $74(9.4-9.8 \mu \mathrm{m})$. Finally, for our simulation LAI magnitudes higher than 5 presents the major difference for ASTER and AHS for different atmospheric levels. However, LAI parameter has to be in concordance with the cell size. In this occasion the height of the cell was constant and lower than $0.5 \mathrm{~m}$. In addition, in DART model, the energy emitted by each leaf cell, is proportional to the vegetation area within the cell (Gastellu-Etchegorry et al. 2004). Moreover, cell LAI must not be too large to obtain accurate simulations. According to Demarez and Gastellu-Etchegorry (2000), cell LAI should be smaller than 0.5, although depending on Earth scenes, larger values tend to lead to inaccurate results, due to the simulation of multiple scattering within the cell. For our results, LAI values were in concordance with the cell size, and accurate results were obtained for LAI values ranged for 0.5 and 2.0 in the most of simulated cases.

In case of LAD sensibility analysis show minimum difference for the whole set of simulations. As for ASTER (figure 11a,b) and AHS (figure 12a,b) at both levels, the differences are minimal. The cell size configuration is accurate for the simulation and the LAD magnitude did not show strong differences between DART and the remotely sensed data. A similar situation was presented for the cell size sensitivity analysis. However, in the case of cell size we varied $X$ and $Y$ dimensions, the height or $Z$ dimension was constant. Therefore, the scene simulated in DART was homogeneous and no strong variation will be expected. The cell size influences the brightness temperature simulated by DART for $Z$ dimension (e.g. $Z$ values higher than $1 \mathrm{~m}$ for GG and LAI higher than 3). The obtained differences can be explained by the possible inaccuracy of input parameters used by DART. This is especially true for vegetation parameters such as LAI. It can be explained also by the discretization scheme $(\Delta X, \Delta Y$, $\Delta Z$ ) used for simulating earth landscapes.

\subsection{Angular measurements and the effect of the cell size, media type and "hot spot effect” in DART comparisons}

The impact of the cell size over BS and GG have been performed for day and nighttime (no shown in this manuscript) and non clear influences in brightness temperature appears when varying the cell size. In this work, several plot of simulation, $100 \%$ cover surface with vegetation type or bare soil were simulated. They are influencing by the atmospheric irradiance estimated from a sounding profile and Modtran mid-latitude atmosphere model. Results presented here did not establish strong angular temperature variations which could be attributed to the low shadow proportion of the scene and arranges of the scene elements (i.e. row or mixed scenes). In fact, DART model can retrieve difference between $25 \mathrm{~K}$ approx. during the daytime between 6 to 14 hours in a crop field, but the average temperature of the scene is influenced by the shadow 
proportion and its temperature instead of the inside canopy temperature. Finally, in this work DART model shows a good agreement with angular measurements as well as in Guillevic et al (2003). Finally, for BS, GG and NS, the simulated angular brightness temperature was similar and no strong influences along the view angle have been reported for the perpendicular plane, although parallel plane presents similar results.

As regards other in-situ measurements and published results, several works have focussed the thermal anisotropy over different natural covers and assessed the so called "hot spot effect" which has been evidenced in some natural surface (Lagouarde et al., 1995; 2000; Smith and Ballard; 2001) and not obviously evidenced (Li et al. 2004). However, in our results this effect is poorly noted for the whole set of in-situ measurements. In theory, this effect occurs in the solar direction when the shadowing proportion is minimum and not be viewed by the sensor. There are few analytical models to simulate this hot spot effect (e.g. Yu et al., 2004; Verhoeff et al., 2007) and some 3-D models (Smith et al., 1997; Gastellu-Etchegorry et al., 2004). Nevertheless, DART model could present this effect when mixed landscape structures are simulated. In any case, the aim of this work is not to evidence the hot spot effect as a major result, but it is important to show that this effect is not even distinguished in angular measurements.

\section{Discussion}

The discrepancy occurred in BS between DART and ASTER products have relation with thermal effects characteristic of the image. The so called "snapshot effect" can occur in agricultural areas where the spatial variability and cover heterogeneity is dominant. The comparison between DART and ASTER products present noticeable errors at BOA and TOA levels. However, over GG results show a good agreement between DART and ASTER products at BOA and TOA. The RMSE is lower than $1 \mathrm{~K}$ and here DART shows its usefulness to simulate remote sensing images with atmospheric contribution. In this case, a homogeneous pixel of vegetation simulated by DART can compare with a pixel of ASTER image.

An important fact in DART and ASTER comparison has relation with the input data. As well known, the TES method used here to estimate the LST, necessary to simulate in DART, presents the gray body problem, although this problem can not affect bare soils (Gillespie et al., 1998), in opposition to vegetation covers. The in-situ temperature measurements carried out over the different samples show standard deviation of 1-2 K due to the thermal heterogeneity of the surfaces, even for closed-canopy vegetated plots, generally assumed to be more homogeneous than soils at the scale of in-situ measurement. Following Balick et al. (2003), we attribute this heterogeneity to turbulence induced temperature changes of the surface or canopy and consequently to the temperature used in DART simulation. Therefore, the TES method used here retrieved the LST values to simulate the brightness temperature and according with the results, this method can be used to generate input values of LST for DART thermal simulation.

On the other side, DART and AHS comparisons at surface level presents a RMSE lower than $1 \mathrm{~K}$ for BS and GG. However, at sensor level strong discrepancies were evidenced. These discrepancies are almost attributed to the atmospheric contribution of the 
greenhouse gases like water vapour and $\mathrm{CO}_{2}$. The rest of AHS thermal bands did not present strong difference, although this is lower at surface level than at sensor level.

There is important to denote that one of DART model drawbacks is the considerable number of input variables required for any simulation. In the thermal spectral range, LSE and LST are key parameters to input in DART model and also those variables are not simple to obtain separately and further algorithms have to be applied. In addition, structural vegetation parameters like LAI and atmospheric vertical profiles have important relevance to accurate simulations regarding atmospheric thermal contribution and vegetation structure for radiative transfer simulation on turbid media. Finally, it is important to denote that, in this work, natural homogenous areas has been simulated, however, the cell size and shadows proportion are strong variables which highly influences the temperature simulated by DART (Guillevic et al, 2003; Sepulcre-Cantó et al., 2009).

As regards to goniometric measurements, DART model showed a good agreement with the in-situ measurements over bare soil and green grass. In fact, the RMSE is lower than $1 \mathrm{~K}$ and the only thermal band with higher values is the $8.1-8.5 \mu \mathrm{m}$ which evidence a different simulated brightness temperature between mono and multispectral modes, although this was explained by the different way to estimate de effective emissivity for each thermal band. On the other hand, for NS results are not satisfactory for the region $8.0-9.0 \mu \mathrm{m}$, due to the spectral properties of the sand emissivity spectra, hence for the other thermal range, difference between 1 and $2 \mathrm{~K}$ has been observed. These results could be affected by the input emissivity parameters or other non clear facts.

\section{Conclusions}

This work shows the potential of DART model for the simulation of thermal remote sensing images at different atmospheric altitudes. Actually, here we analyzed the brightness temperatures simulated by DART capabilities with atmospheric contribution over three opposite ground covers like green grass, bare soil and sand. DART brightness temperatures proved to be well related with brightness temperature estimated by the AHS thermal imagery and ASTER products. For green grass cover, the RMSE obtained between DART and ASTER products were less than $1 \mathrm{~K}$ as well as for DART and AHS comparison if the strong absorption bands are not considered. For bare soil, results were affected for a not frequently thermal effect in the case of ASTER images, while for the AHS imagery, the emissivity spectra could be influence the land leaving radiance simulated by DART in bands with strong atmospheric absorption. Moreover, DART 3D model presents a good tool to simulate angular brightness temperature over homogenous areas where non gap proportion exists. Additionally, the cell size do not generate a strong influence when the landscape simulation is homogenous

Finally, this work stressed the potential of DART model to simulate remotely sensed brightness temperatures. As such, it is a useful tool for remote sensing studies and also for the calibration of airborne sensors. Obviously, its great advantages lie in the possibility to work with 3-D simulations of Earth landscapes. This potential has just been improved DART 4 release with the possibility to simulate vegetation covers as the juxtaposition of discrete translucent geometric elements and not only as the juxtaposition of turbid cells. 


\section{Acknowledgement}

The authors wish to thank in part to the Ministerio de Educación y Ciencia (TERMASAT, project ESP2005-07724-C05-04; EODIX project AYA2008-0595-C0401), for their financial support, in addition to the European Union (CEOP-AEGIS, project FP7-ENV-2007-1 proposal No. 212921; WATCH, project 036946).

\section{References}

Abrams, M. 2000. The Advanced Spaceborne Thermal Emission and Reflection Radiometer (ASTER): Data products for the high spatial resolution image on NASA's Terra platform. International Journal of Remote Sensing, 21(5), 847 - 859.

Baldridge, A.M., Hook, S.J., Grove, C.I. and Rivera, G. 2009. The ASTER spectral library version 2.0. Remote Sensing of Environment, 113(4), 711-715.

Balick, L.K., B.A. Hutchinson, J.A. smith, and M.J. McGuire. 1987. Directional thermal exitance distributions of a deciduous forest in summer. IEEE trans. Geosci. Remote sensing, 25, $410-412$.

Balick, L.K., Jeffery , C.A. and Henderson, B.G. 2003. Turbulence induced spatial variation of surface temperature in high-resolution thermal IR satellite imagery. Proceedings of SPIE, Vol. 4879. (pp. 221-230), Crete, Greece: Society of PhotoOptical Instrumentation Engineers.

Berk, A., Anderson, G.P., Acharya, P.K., Chetwynd, J.H., Bernstein, L.S., Shettle, E.P., Matthew, M.W. and Adler-golden, S.M., 1999, MODTRAN4 User's Manual. Air Force Research Laboratory, Space Vehicles Directorate, Hanscom AFB, MA 01731-3010.

Chehbouni, A., Nouvellon, Y., Kerr, Y., Moran, M., Watts, C., Prévot, L., Goodrich, D. and Rambal, S. 2001, Directional effect on radiative surface temperature measurements over a semiarid grassland site. Remote Sensing of Environment, 76, 360 - 372.

Cuenca, J. and Sobrino, J.A. 2004. Experimental measurements for studying angular and spectral variation of thermal infrared emissivity. Applied Optics, 43, $4598-4602$.

Demarez, V., Gastellu-Etchegorry, J.P., Mordelet, P., Tosca, C., Marty, G. and Guillevic, P. 2000. Modeling of the radiation regime and photosynthesis of a finite canopy using the DART model. Influence of canopy architecture assumptions and border effects. Agronomy Journal, 20, $259-270$.

Demarez, V. and Gastellu-Etchegorry, J.P. 2000. A modelling approach for studying forest chlorophyll content. Remote Sensing of Environment, 71, 226 - 238.

Duthoit, S., Demarez, V., Gastellu-Etchegorry, J.P., Martin, E. and Rujean, J.L. 2008. Assessing the effects of the clumping phenomenon on BRDF of a maize crop based on 3D numerical scenes using DART model. Agricultural and Forest Meteorology, 148, $1341-1352$. 
Gascon, F., Gastellu-Etchegorry, J.P. and Lefévre, M.J., 2001, Radiative transfer model for simulating high-resolution satellite images. IEEE Transactions on Geoscience and Remote Sensing, 39(9), 1922 - 1926.

Gascon, F., Gastellu-Etchegorry, J.P., Lefèvre.Fonollosa and Dufrene, E. 2004. Retrieval of forest biophysical variables by inverting a 3-D radiative transfer model and using high and very high resolution imagery. International Journal of Remote Sensing, $25(24), 5601-5616$.

Gastellu-Etchegorry, J.P. 2008. 3D modeling of satellite spectral images, radiation budget and energy budget of urban landscapes. Meteorology and Atmospheric Physics, $102,187-207$.

Gastellu-Etchegorry, J.P. 2007, DART handbook. CESBIO, http://www.cesbio.upstlse.fr/us/dart.htm, $85 \mathrm{pp}$.

Gastellu-Etchegorry, J.P, Demarez, V., Pinerl, V. and Zagolski, F. 1996. Modeling radiative transfer in heterogeneous 3D vegetation canopies. Remote Sensing of Environment, 58, $131-156$.

Gastellu-Etchegorry, J.P. and Trinchon, V. 1998. A modeling approach of PAR environment in a tropical rain forest in Sumatra: application to remote sensing. Ecological Modelling, 108, 237 - 264.

Gastellu-Etchegorry, J.P., Guillevic, P., Zagolski, F., Demarez, V., Trinchon, V., Deering, D. and Leroy, M. 1999. Modeling BRF and radiation regime of boreal and tropical forests: I. BRF. Remote Sensing of Environment, 68, $281-316$.

Gastellu-Etchegorry, J.P., Martin, E. and Gascon, F. 2004. DART: a 3D model for simulating satellite images and studying surface radiation budget. International Journal of Remote Sensing, 25(1), 73- 96.

Gillespie, A., Rokugawa, S., Matsunag, T., Cothern, J.S., Hook, S. and Khale, A.B., 1998. A temperature and emissivity separation algorithm for advance spaceborne thermal emission and reflection radiometer (ASTER) images. IEEE Transactions and Geoscience and Remote Sensing, 36. 1113 - 1126.

Guillevic, P. and Gastellu-Etchegorry, J.P. 1999, Modeling BRF and radiation regime of boreal and tropical forest: II. PAR Regime. Remote Sensing of Environment, 68, 317 340 .

Guillevic, P., Gastellu-Etchegorry, J.P., Demarty, J. and Prévot, L. 2003. Thermal infrared radiative transfer within three-dimensional vegetation covers. Journal of Geophysical Research, 108, D8, 4248, DOI:10.1029/2002JD002247.

Jiménez-Muñoz, J.C and Sobrino, J.A. 2006. Emissivity spectra obtained from field and laboratory measurements using the temperature and emissivity separation algorithm. Applied Optics, 45(27), $7104-7109$. 
Kealy P.S. and S. J. Hook, 1993. Separating temperature and emissivity in thermal infrared multispectral scanner data: Implications for recovering land surface temperatures. IEEE Trans. Geosc. Rem. Sens. 31, 1155-1164.

Kimes, D.S. and Kirchner, J.A., 1983, Directional radiometric measurements of rowcrop temperatures. International Journal of Remote Sensing, 4(2), 299 - 311.

Lagouarde, J.P., Kerr, Y.H. and Brunet, Y. 1995. An experimental study of angular effects on surfaces temperatures for various plant canopies and bare soils. Agricultural and Forest meteorology, 77, $167-190$.

Lagouarde, J.P., Ballands, H., Moreau, P., Guyon, D. and Corabeouf, D. 2000, Experimental study of brightness surface temperature angular variations of maritime pine (Pinus Pinaster) stands. Remote Sensing of Environment, 72, 17 - 34.

Li, Z.-L., Zhang, R., Sun, X., Su, H., Tang, X., Zhu, Z. and Sobrino, J.A. 2004. Experimental system for the study of the directional thermal emission of natural surfaces. International Journal of Remote Sensing, 25(1), 195 - 204.

Martínez, B., García-Haro, F.J. and Camacho de Conca, F. 2009. Derivation of highresolution leaf area index maps in support of validation activities: Application to the cropland Barrax site. Agriculture and Forest Meteorology, 149, 130 - 145.

McAtte, B.K., Prata, A.J. and Lunch, M.J. 2003, The angular behaviour of emitted thermal infrared radiation $(8-12 \mu \mathrm{m})$ at a semiarid site. Journal of Applied Meteorology, 42, 1060-1071.

Menenti, M., Jia, L. and Li, Z.L. 2008. Multiangular thermal infrared observations of terrestrial vegetation in Advances in Land Remote Sensing: system, Modeling, Inversion and Application. Ed. Shunlin Liang. Springer, 498 pp.

Moersch, J.E. and Christensen, P.R. 1995. Thermal emission from particulate surfaces: A comparison of scattering models with measured spectra. Journal of Geophysical Research, 100, $7465-7477$.

Moreno, J., Calera, A., Caselles, V., Cisneros, J.M., Martínez-Lozano, J.A., Meliá, J., Montero, F. and Sobrino, J.A. 2001. The measurement programme at Barrax, in DAISEX Final Results Workshop, NASA Spec. Publ., SP-499, pp. 43- 51,

Moreno, J. and Co-Authors. 2004. The SPECTRA Barrax Campaign (SPARC): Overview and first results from CHRIS data, in: Proceedings of $2^{\text {nd }}$ CHRIS/PROBA Workshop, Frascati, Italy, ESA-ESRIN, CD-ROM.

Payan, A. and Royer, A. 2004. Analysis of Temperature and Emissivity Separation (TES) algorithm applicability and sensitivity. International Journal of Remote Sensing, 25(1), 15-37.

Pinheiro, A.C., Privette, J.L., Mahoney, R. and Tucker, C. 2004. Directional effects in a daily AVHRR land surface temperature dataset over Africa. IEEE Transactions on Geoscience and remote sensing, 42(9), 1941 - 1954. 
Ross, J. 1981. The radiation regime and architecture of plant stands. W. Junk, The Hague, The Netherlands, $391 \mathrm{pp}$.

Sepulcre-Cantó, G., Zarco-Tejeda, P.J., Sobrino, J.A., Berni, J.A.J., Jiménez-Muñoz, J.C. and Gastellu-Etchegorry, J.P. 2009. Discriminating irrigated and rainfed olive orchards with thermal ASTER imagery and DART 3D simulation. Agricultural and Forest Meteorology, 149, $962-975$.

Smith, J.A. and Ballard, J.R. Jr. 2001. Thermal infrared hot spot and dependence on canopy geometry. Optical Engineering, 40(8), 1435 - 1437.

Smith, J.A., Chauhan, N.S., Schmugge, T.J., Ballard, J.R. 1997. Remote Sensing of land surface temperature: the directional viewing effect. IEEE Trans. Geosci. Remote Sensing, 35, $972-974$.

Sobrino, J.A. and Cuenca, J. 1999. Angular variation of thermal infrared emissivity for some natural surfaces from experimental measurements. Applied Optics, 38(18), 3931 3936.

Sobrino, J.A., Jiménez-Muñoz, J.C., Verhoef, W. 2005. Canopy directional emissivity: comparison between models. Remote sensing of Environment, 99, 304 - 314.

Sobrino, J.A., Jiménez-Muñoz, J.C., Zarco-Tejeda, P.J., Sepulccre-Cantó, G. and de Miguel, E. 2006. Land surface temperature derived from airborne hyperspectral scanner thermal infrared data. Remote Sensing of Environment, 102, 99 - 115.

Sobrino, J.A, Jiménez-Muñóz, J.C., Balick, L., Gillespie, A., Sabol, D. and Gustafson W. 2007. Accuracy of ASTER Level-2 thermal-infrared Standard Products of an agricultural area in Spain. Remote Sensing of Environment, 106, $146-153$.

Sobrino, J.A. and Co-Autors. 2008. Thermal remote sensing in the framework of the SEN2FLEX project: field measurements, airborne data and applications. International Journal of Remote Sensing, 29(17-18), 4961 - 4991.

Sobrino, J.A. and Co-Authors. 2009a. Thermal remote sensing from Airborne Hyperspectral Scanner data in the framework of the SPARC and SEN2FLEX projects: an overview. Hydrol. Earth Syst. Sci., 13, 2031-2037.

Sobrino, J.A., Mattar, C., Pardo, P., Jiménez-Muñoz, J.C., Hook, S., Baldridge, A. and Ibañez, F. 2009b. Soil emissivity and reflectance spectra measurements. Applied Optics, 48(19), 3664-3670

Verhoef, W., Jia, L., Xiao, Q. And Su, Z. 2007. Unified optical-thermal four-stream radiative transfer theory for homogeneous vegetation canopies. IEEE Transanctions on geoscience and remote sensing, 45(6), $1808-1822$.

Voogt, J.A. and Oke, T.R., 1997, Complete urban surface temperature. Journal of Applied Meteorology, 36, 1117-1132. 
Voogt, J.A. and Oke, T.R., 1998, Effects of urban surface geometry on remotely-sensed surface temperature. International Journal of Remote Sensing, 19(5), 895 - 920.

Widlowski, J.L., and Co-Authors. 2007. The third RAdiation transfer Model Intercomparison (RAMI) exercise. Journal of Geophysical Research, 112, D09111, doi: 10.1029/2006JD007821.

Widlowski, J.L., Robustelli, M., Disney, M., Gastellu-Etchegorry, J.P., Lavergne, T., Lewis, P., North, P.R.J., Pinty, B., Thompson, R. and Verstraete, M.M. 2008. The RAMI On-line Model Checker (ROMC): A web-based benchmarking facility for canopy reflectance models. Remote Sensing of Environment, 112, 1144 - 1150.

Yu, T., Gu, X., Tian, G., Legrand, M., Baret, F., Hanocq, J.F., Bosseno, R. and Zhang, Y. 2004. Modeling Directional brightness temperature over a maize canopy in row structure. IEEE Transactions on Geoscience and Remote Sensing, 42(10), 2290 - 2304. 


\section{LIST OF FIGURES}

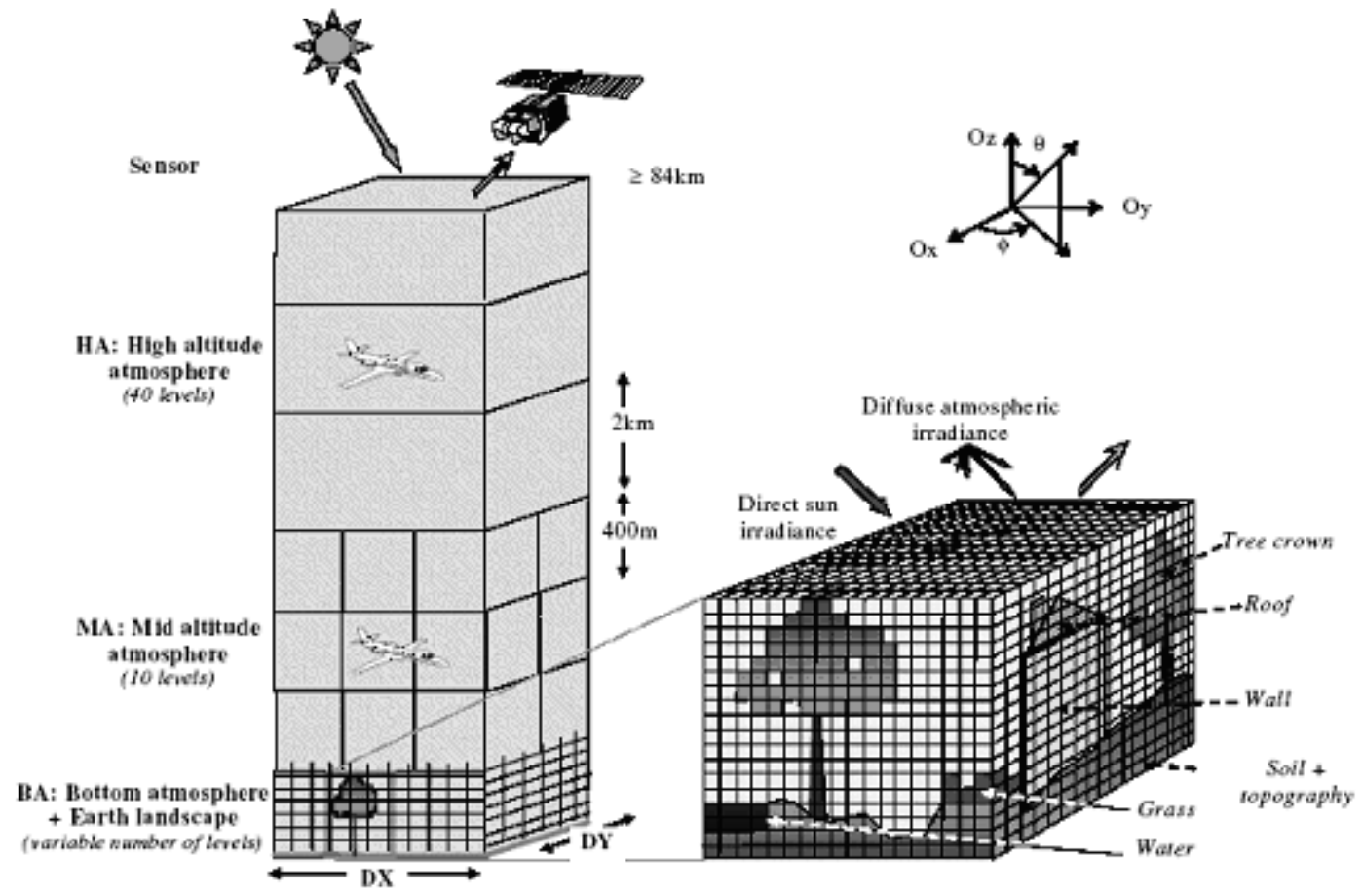

Figure 1. Schematic simulation of the DART "landscape-atmosphere-sensor" system (adapted from DART Handbook, 2007)
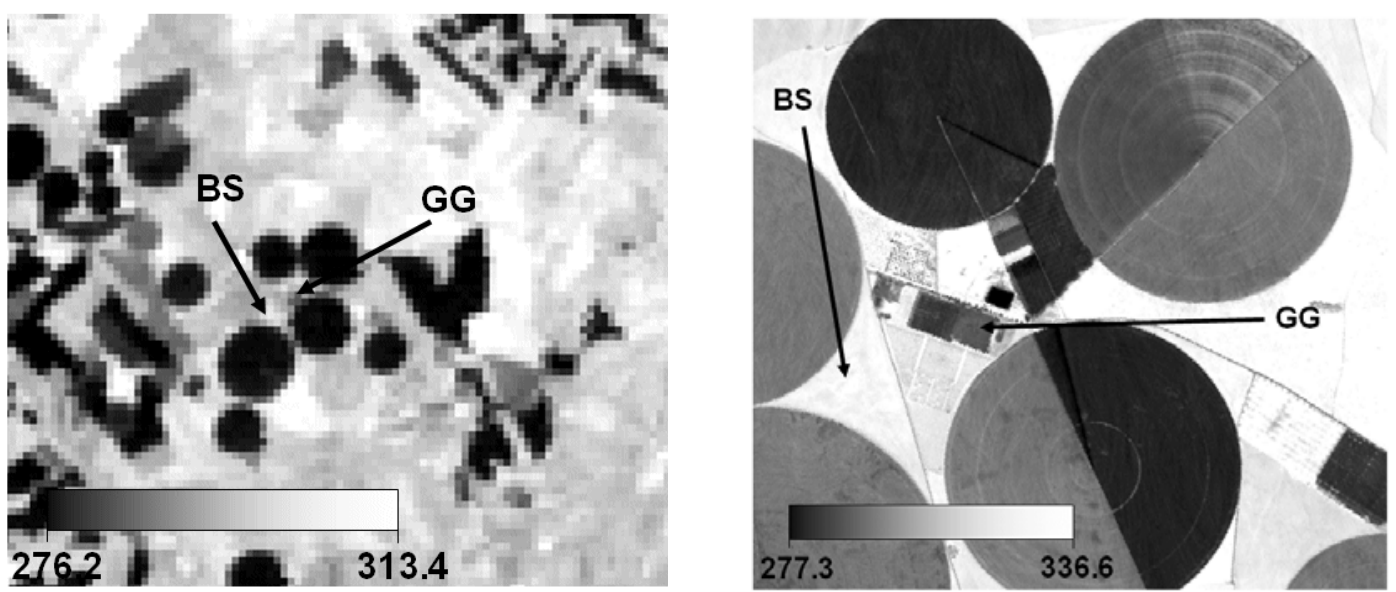

Figure 2. Barrax test site for ASTER thermal band $10(8.1-8.5 \mu \mathrm{m})$ during SPARC 2004 (left) and AHS band $74(9.38-9.81 \mu \mathrm{m})$ during SEN2FLEX 2005 (right). Bare soil (BS) and green grass (GG) locations were remarked. Figures also shown the temperature at-sensor levels which values are given in $\mathrm{K}$. 

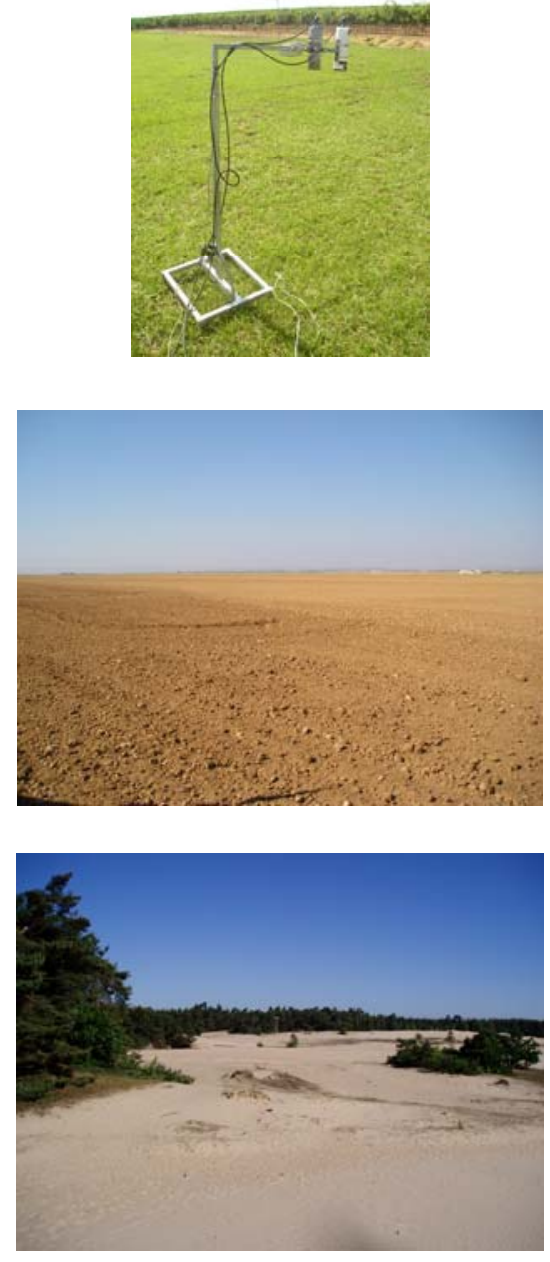

(c)

(b)
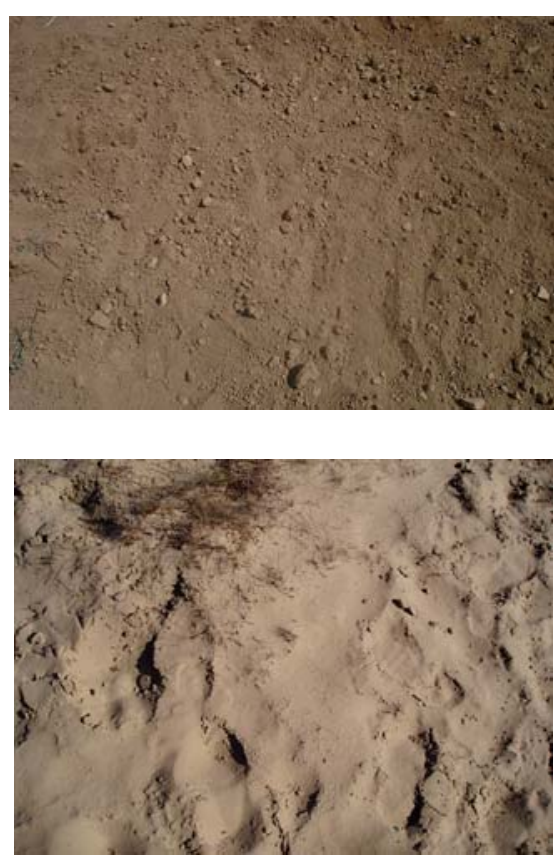

Figure 3. Goniometric system and the measured samples (a) GG, (b) BS and (c) NS. Left column pictures show the panoramic view and right column a zoom in view. 


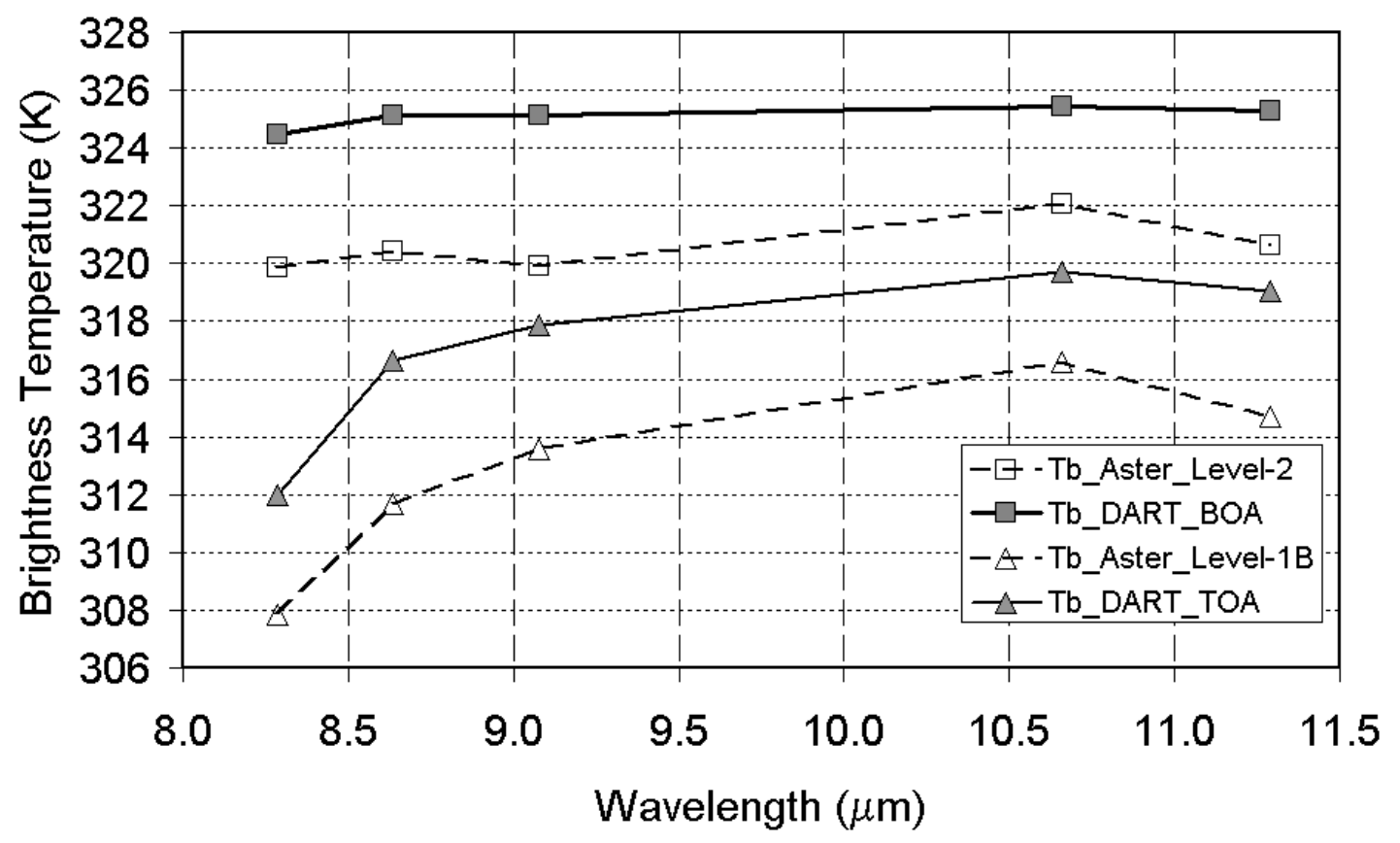

(a)

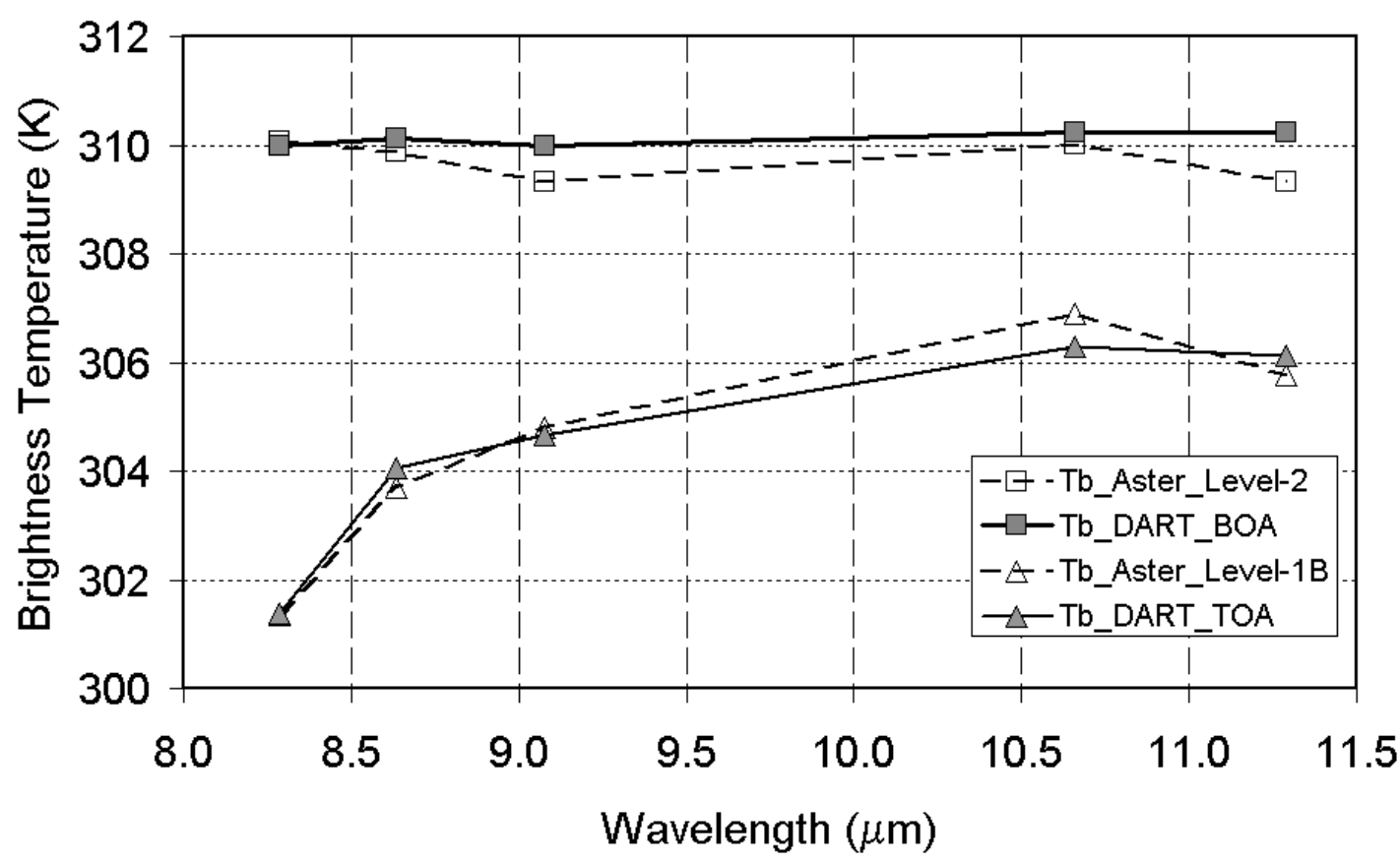

(b)

Figure 4. Brightness temperature $(\mathrm{Tb})$ for bare soil (a) and green grass (b) simulated by DART at BOA and TOA levels. The plot also shows the Tb estimated from the ASTER level-1 and level -2 imagery. 


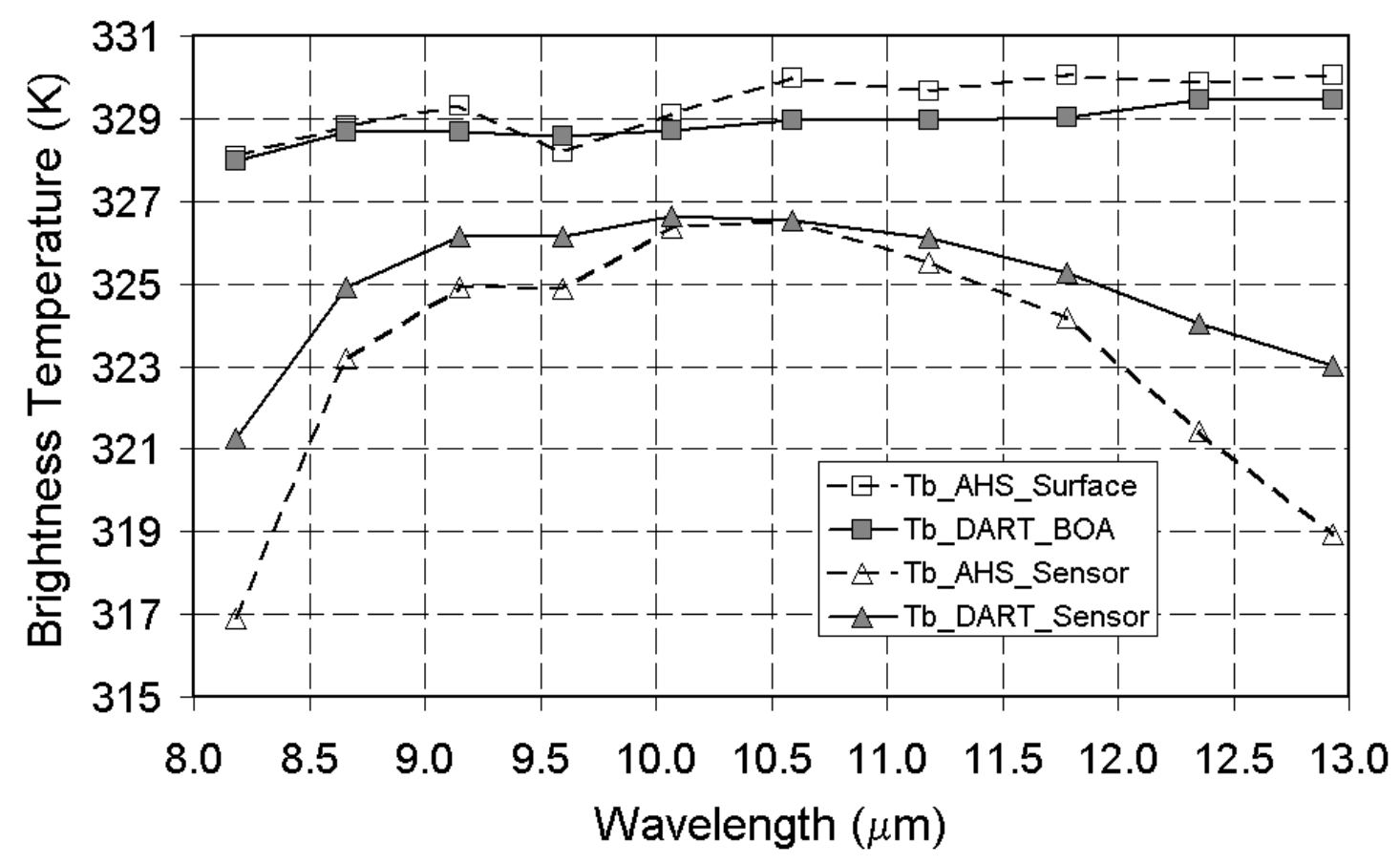

(a)

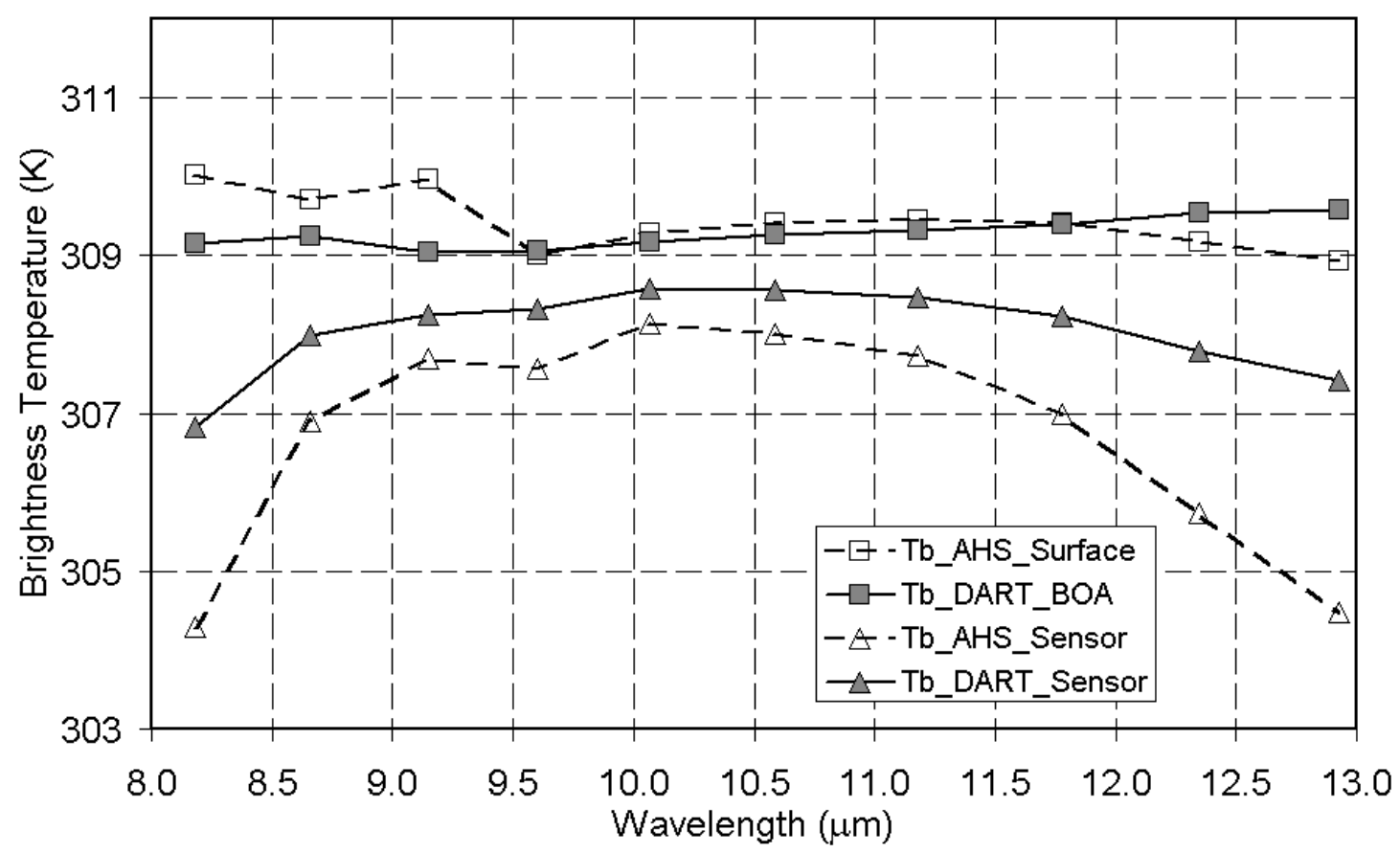

(b)

Figure 5. Brightness temperature ( $\mathrm{Tb}$ ) for bare soil (a) and green grass (b) simulated by DART at surface and sensor levels. The plot also shows the Tb estimated from the AHS imagery. 


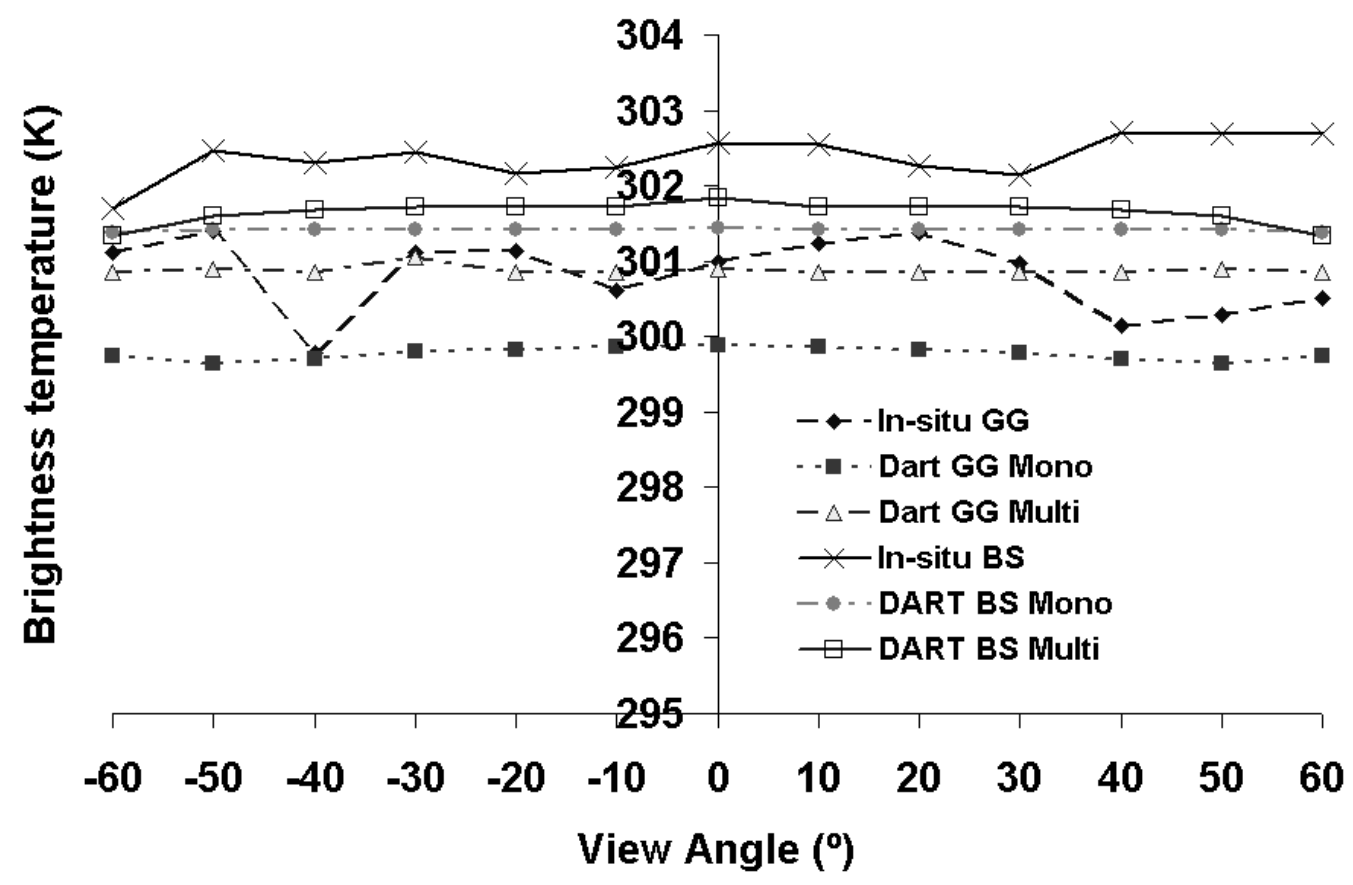

(a)

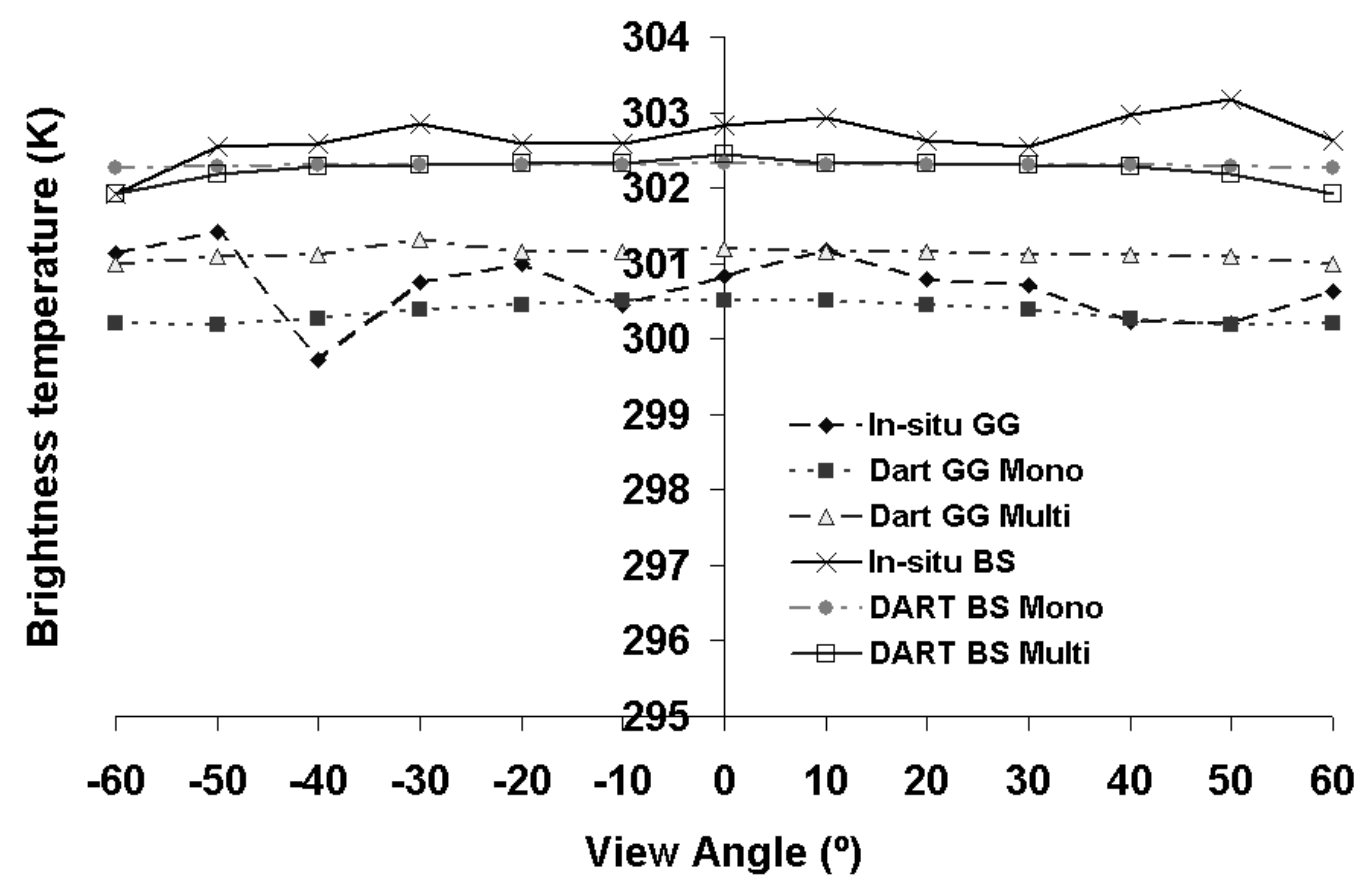

(b) 


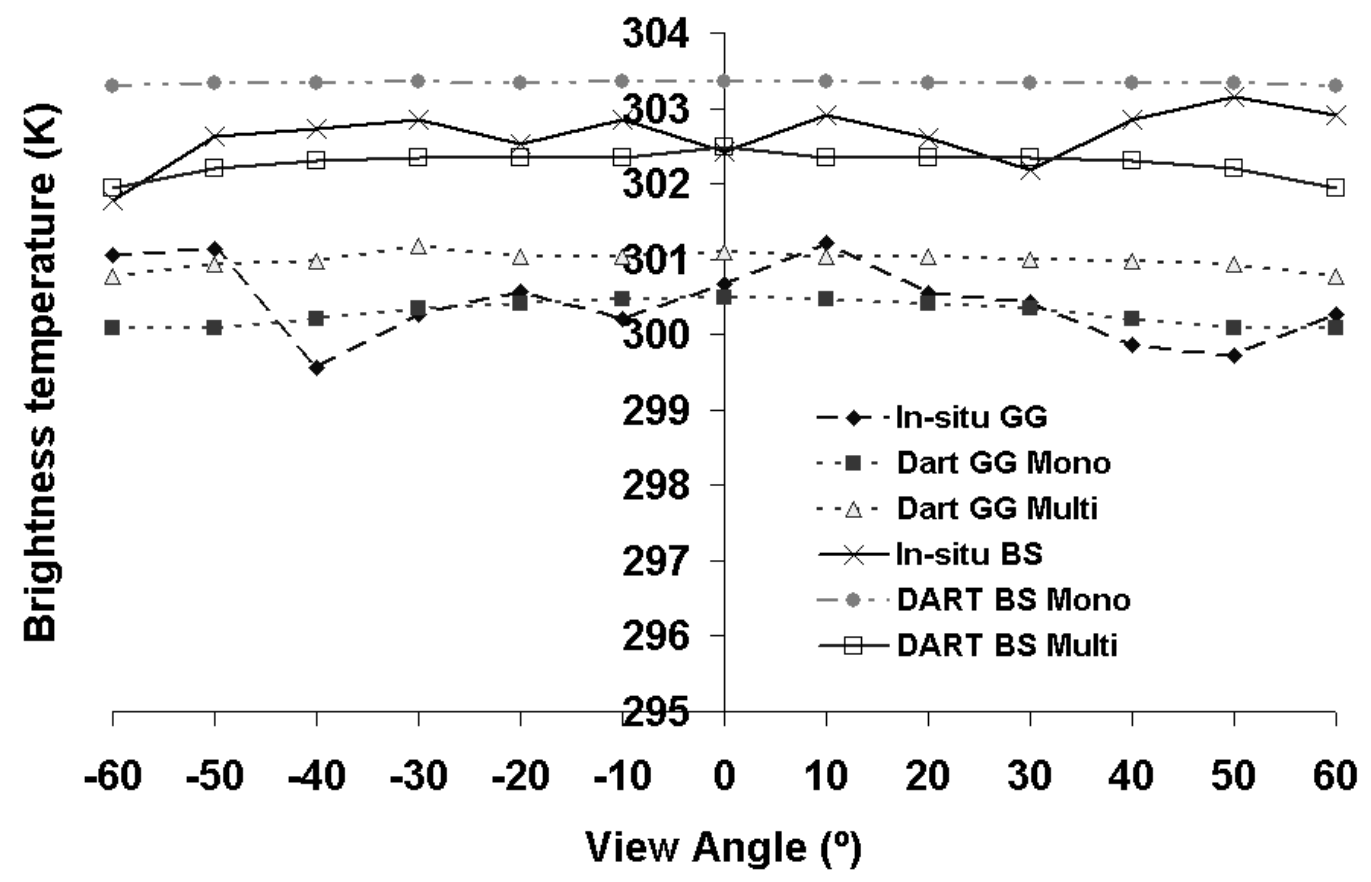

(c)

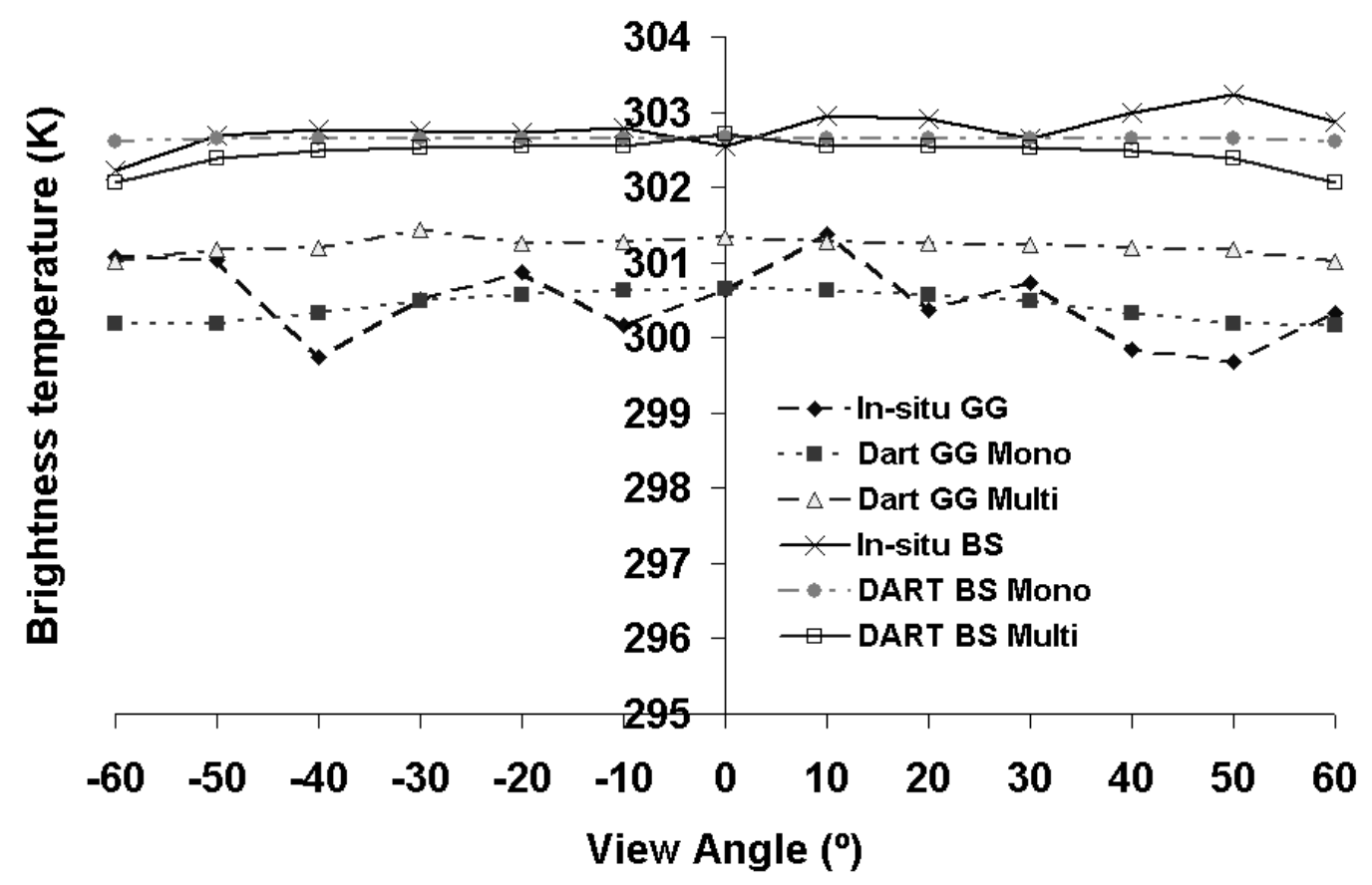

(d) 


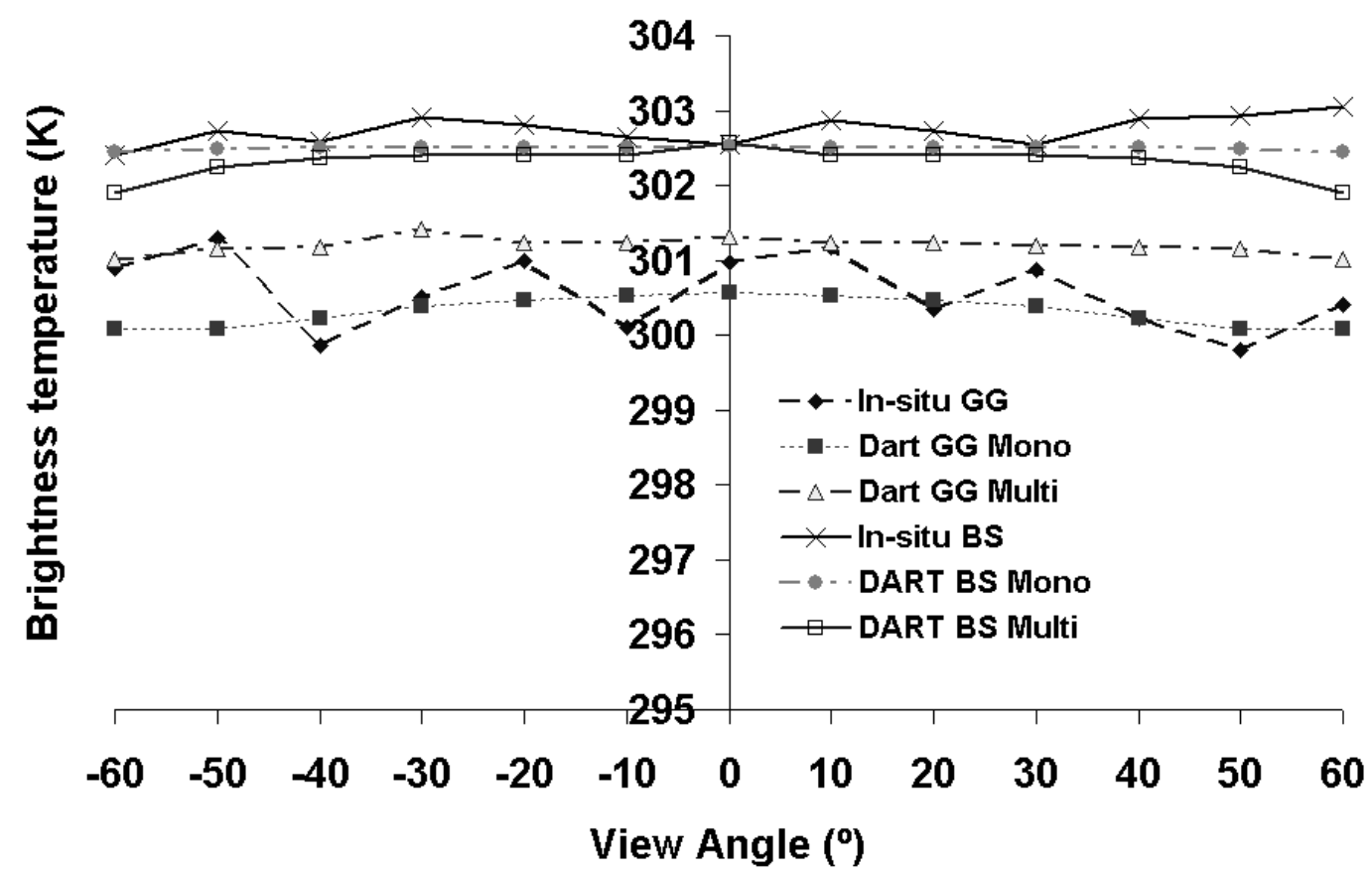

(e)

Figure 6. Simulated and measured angular brightness temperature at (a) $8.1-8.5 \mu \mathrm{m}$, (b) $8.5-8.9 \mu \mathrm{m}$, (c) $8.9-9.3 \mu \mathrm{m}$, (d) $10.3-11.0 \mu \mathrm{m}$ and (e) $11.0-11.7 \mu \mathrm{m}$, for day time over green grass (GG) and bare soil (BS) surfaces for each thermal band. It was also shown the DART simulations and in-situ measurements. Results are presented for solar plane. 


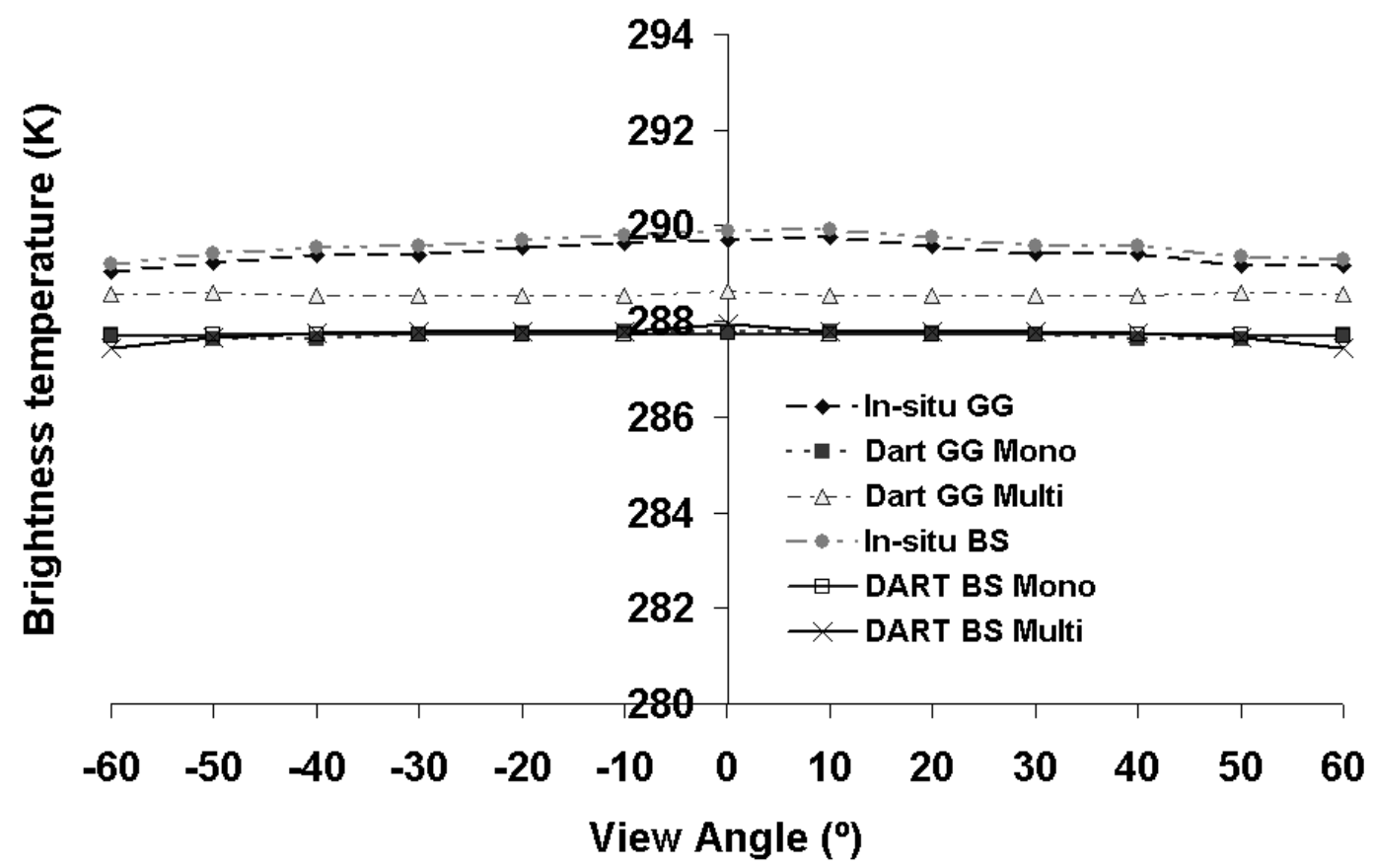

(a)

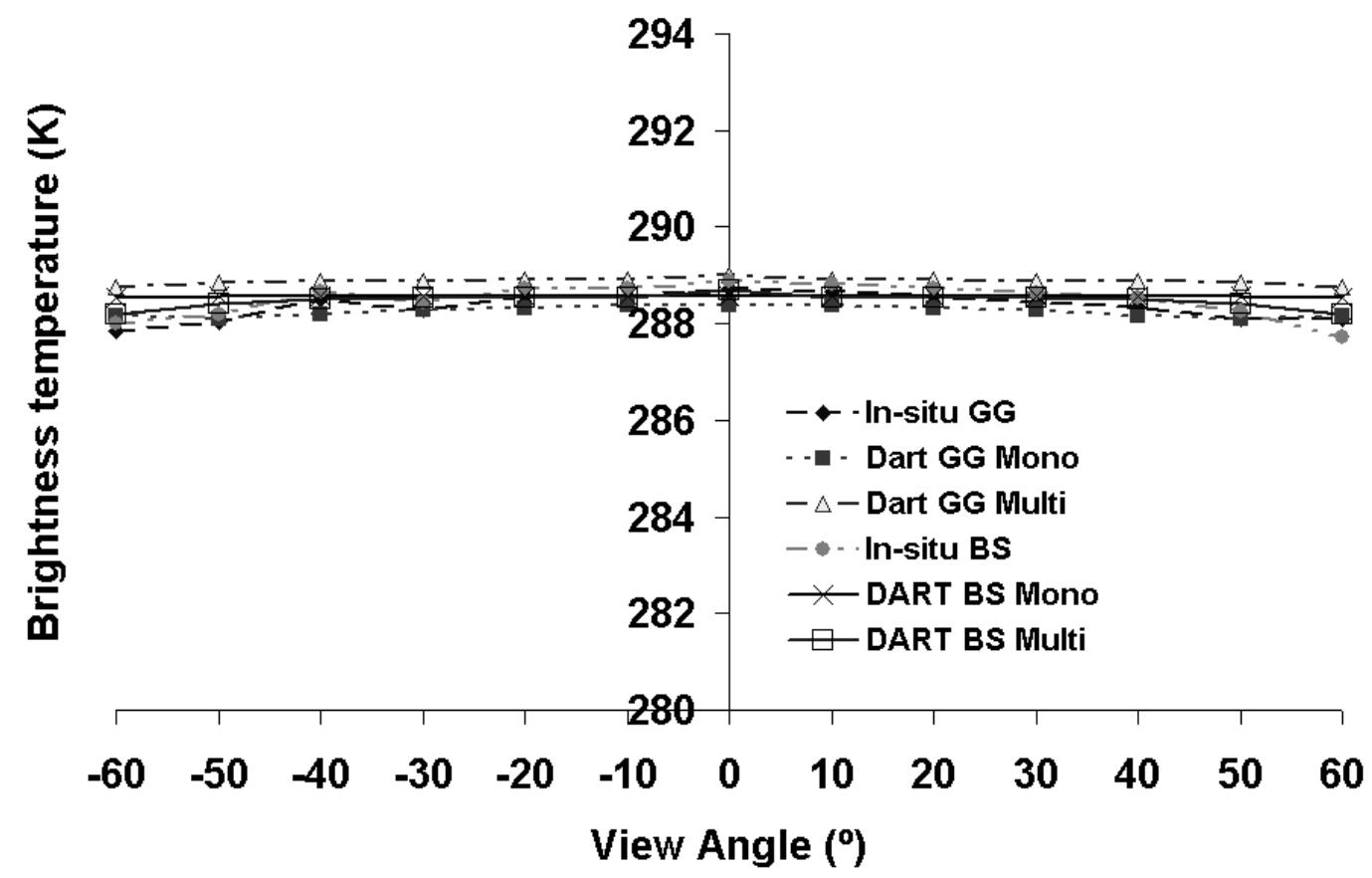

(b) 


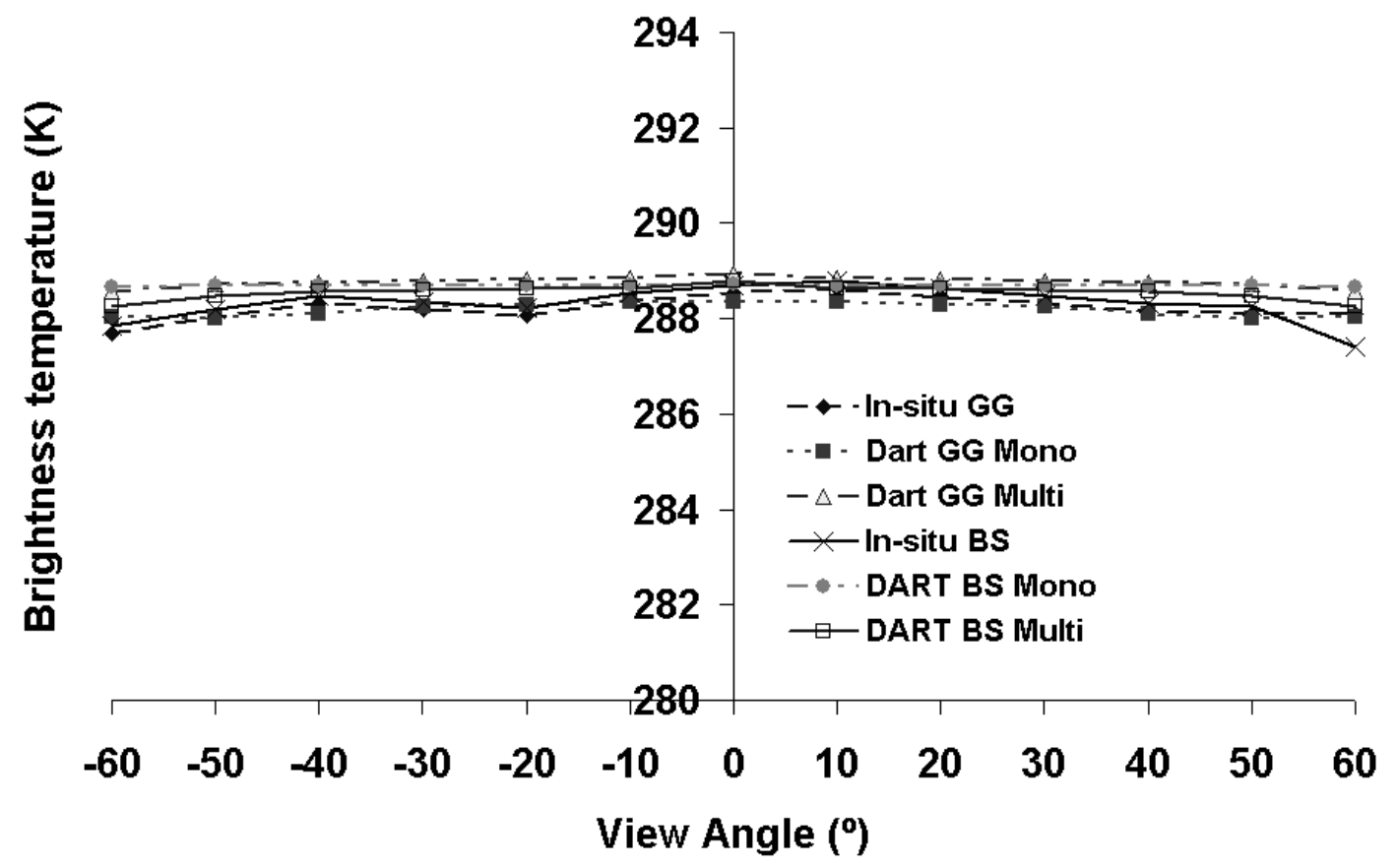

(c)

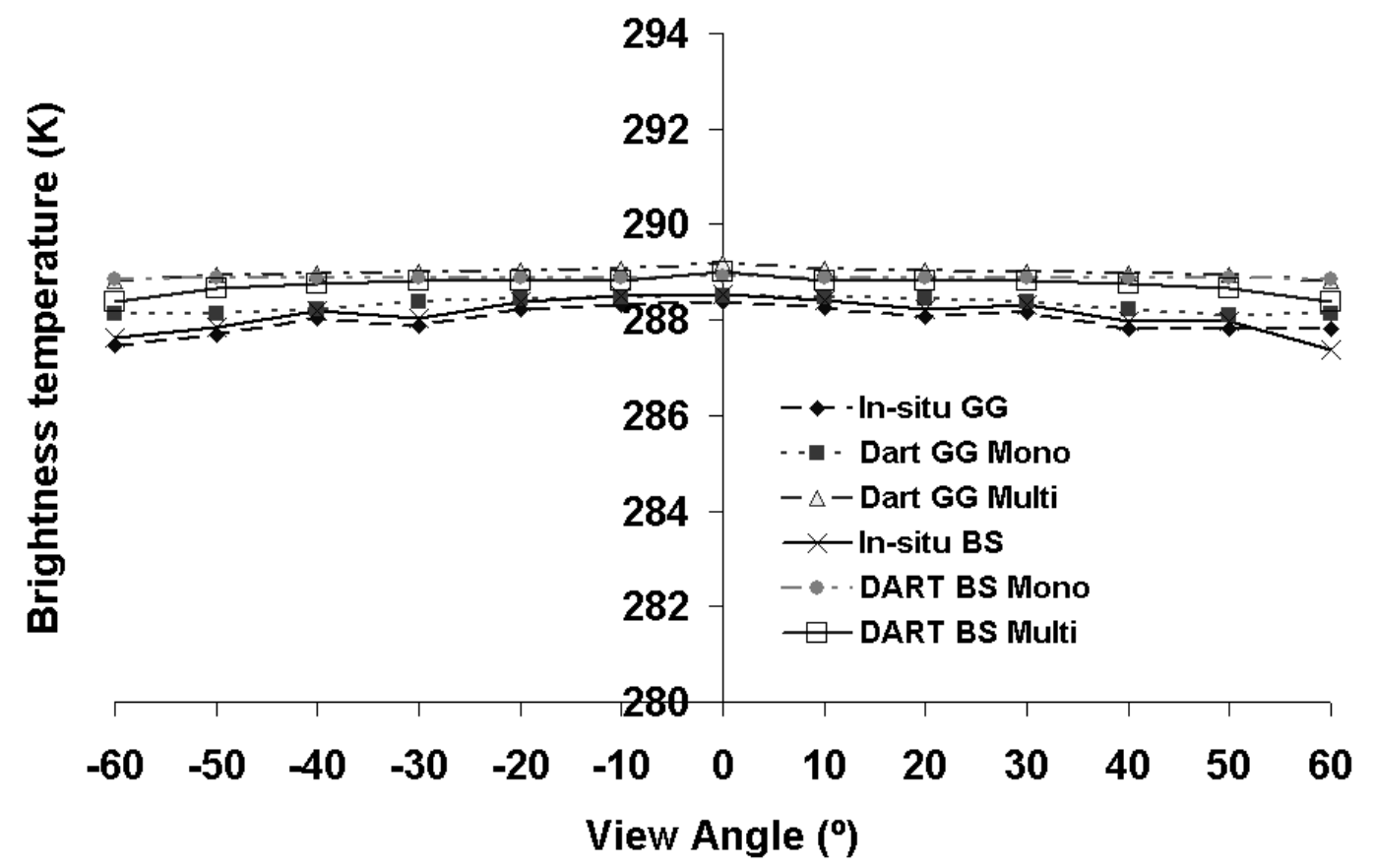

(d) 


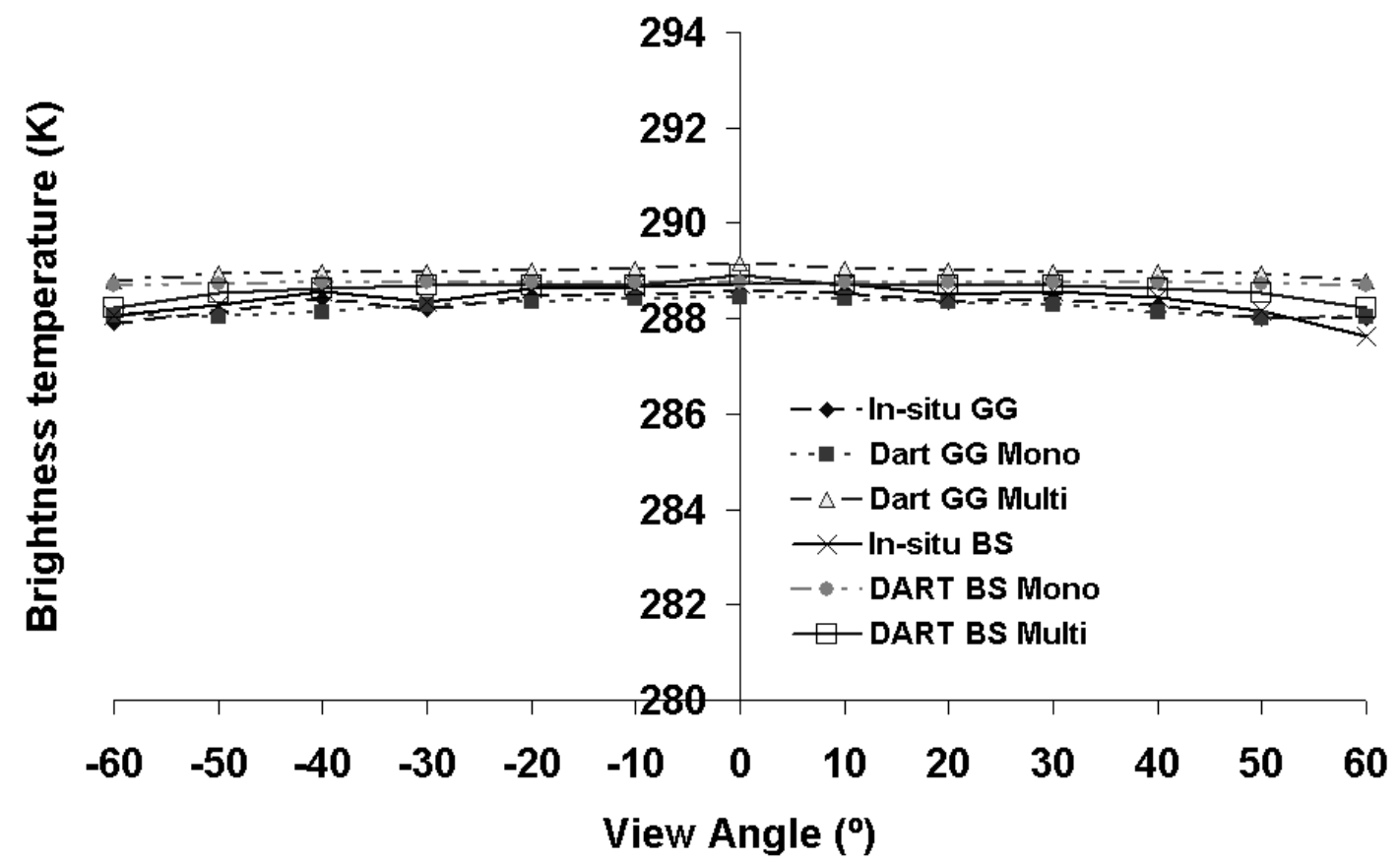

(e)

Figure 7. Simulated and measured angular brightness temperature at (a) $8.1-8.5 \mu \mathrm{m}$, (b) $8.5-8.9 \mu \mathrm{m}$, (c) $8.9-9.3 \mu \mathrm{m}$, (d) $10.3-11.0 \mu \mathrm{m}$ and (e) $11.0-11.7 \mu \mathrm{m}$, for nighttime over green grass (GG) and bare soil (BS) surfaces for each thermal band. It was also shown the DART simulations and in-situ measurements. Results are presented for solar plane. 


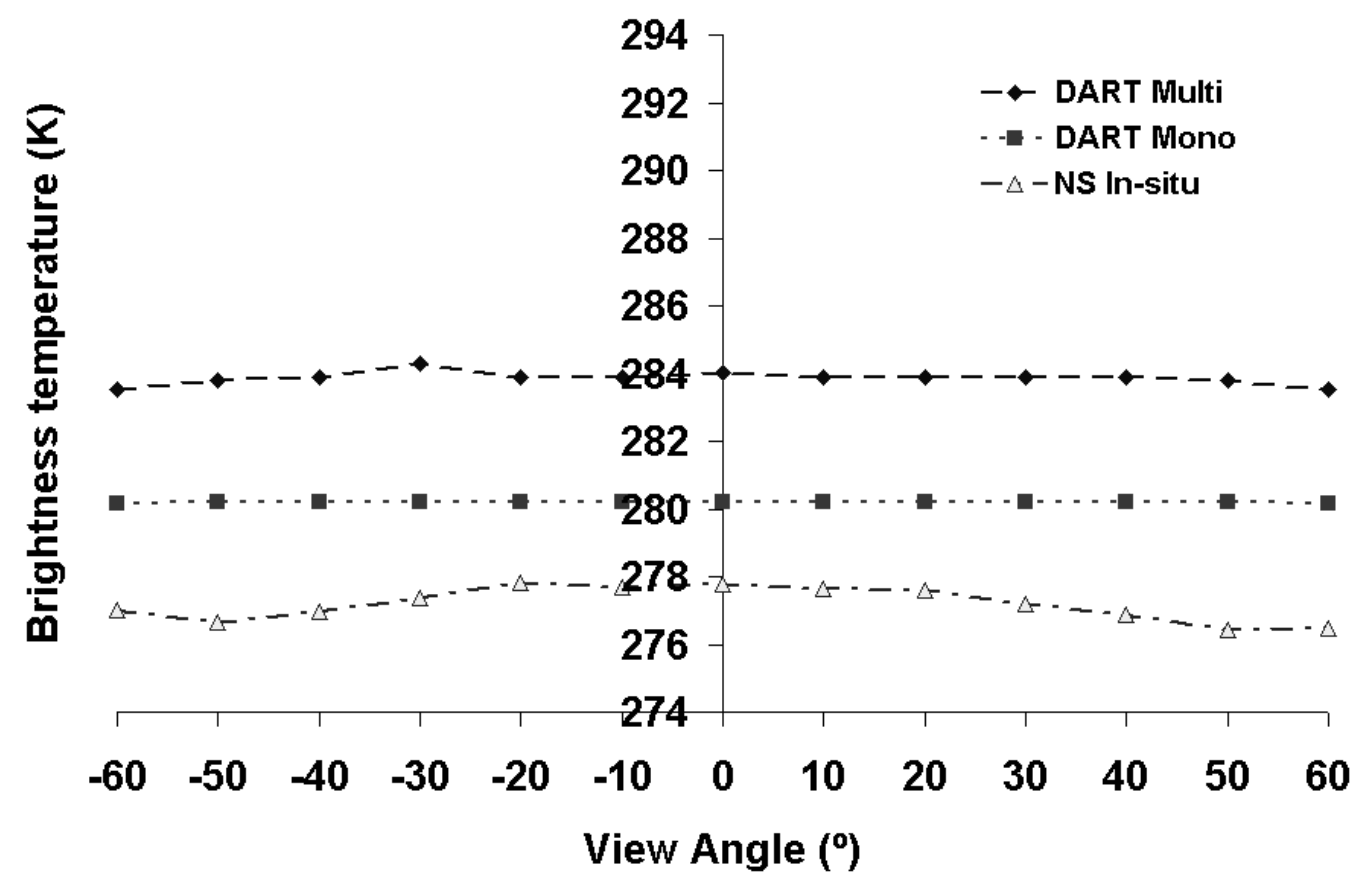

(a)

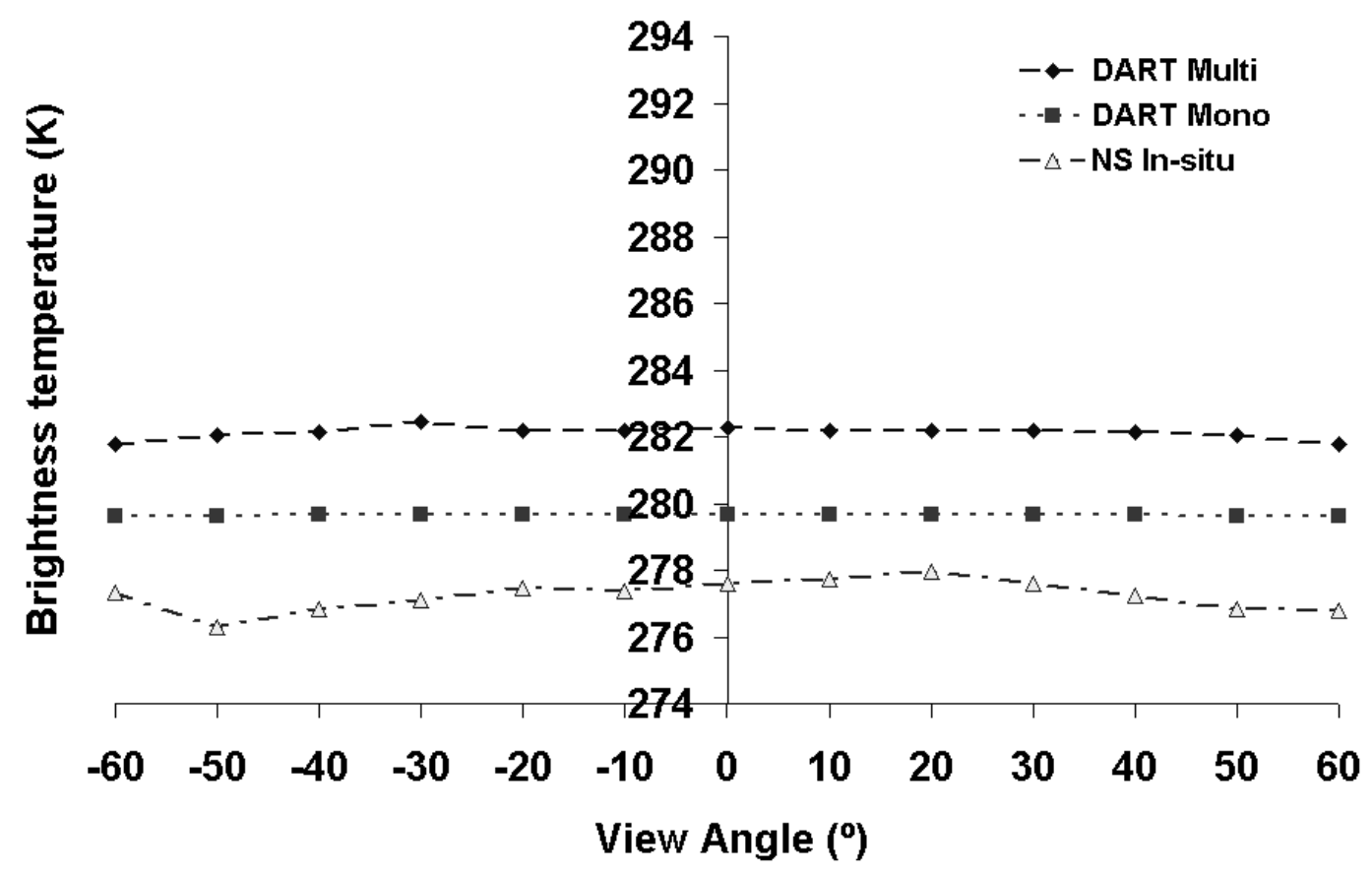

(b) 


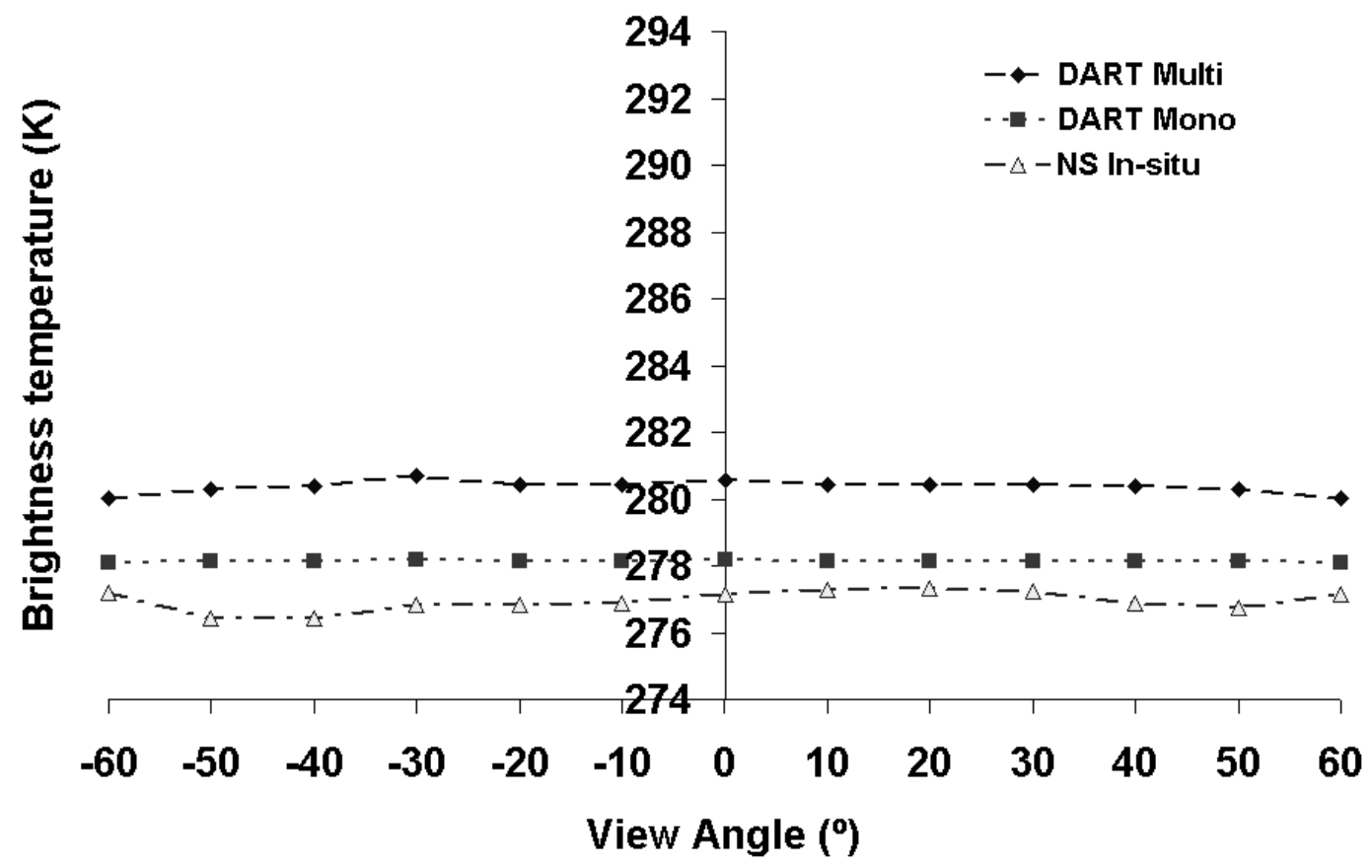

(c)

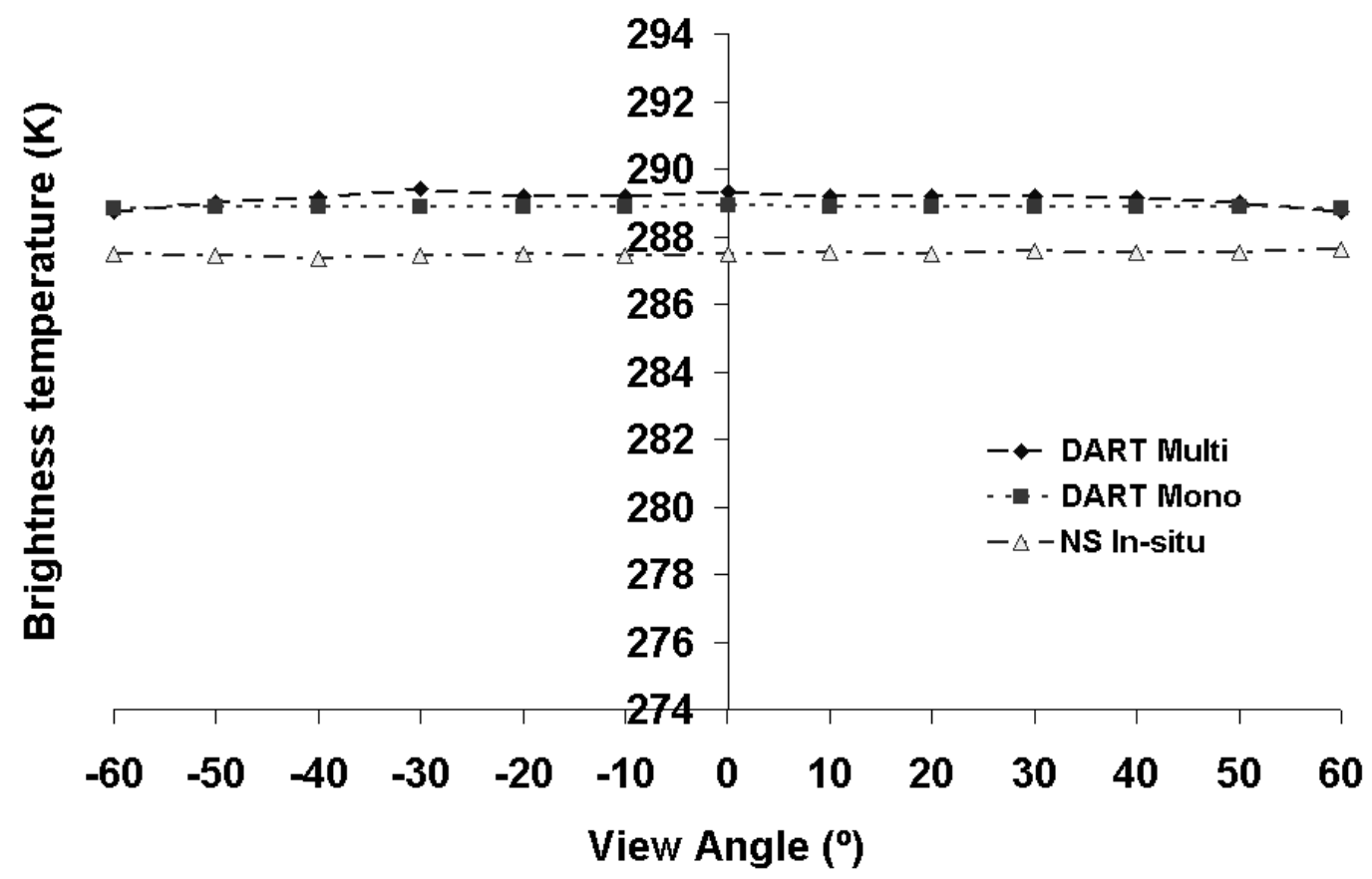

(d) 


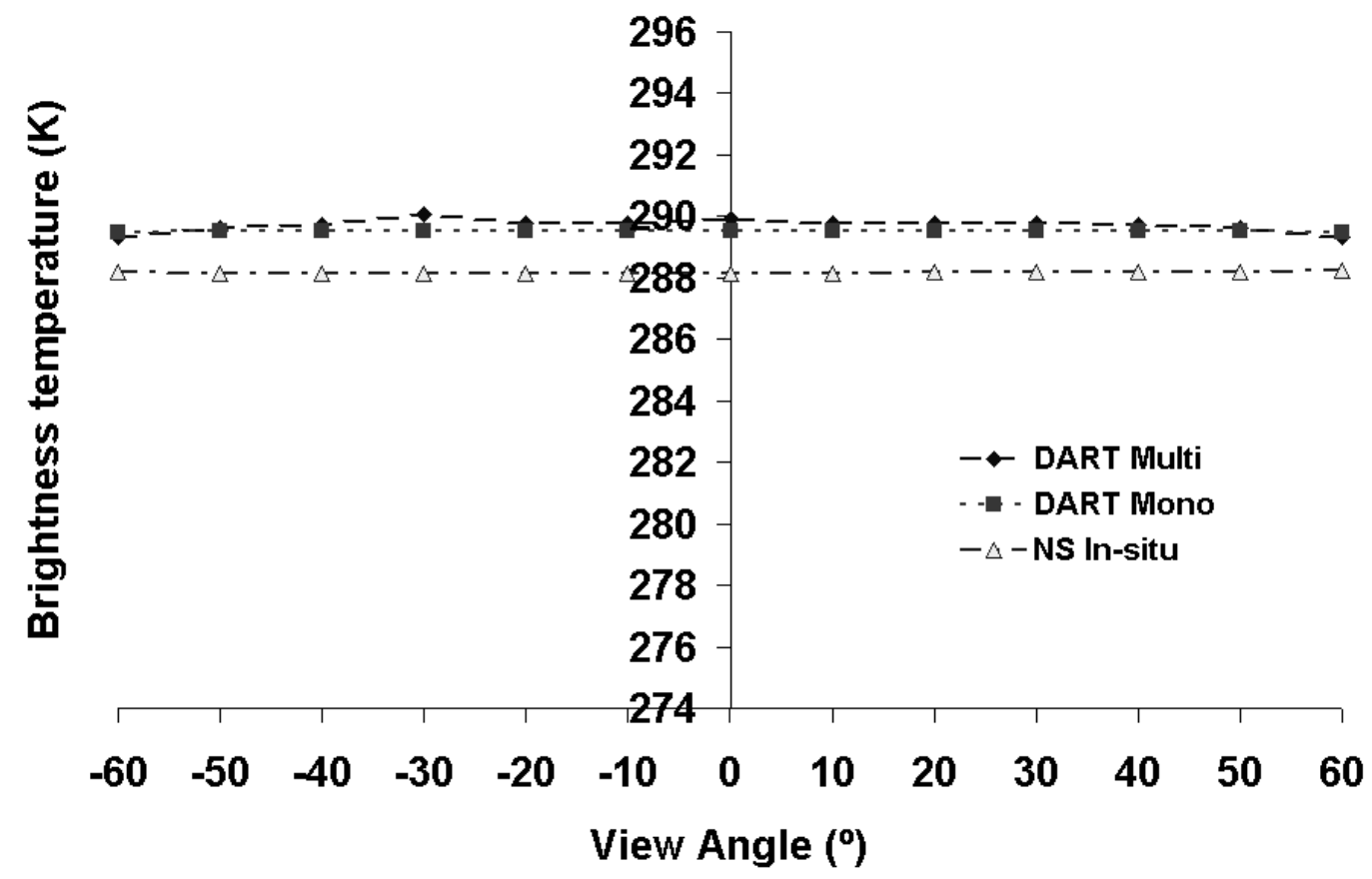

(e)

Figure 8. Simulated and measured angular brightness temperature at (a) $8.1-8.5 \mu \mathrm{m}$, (b) $8.5-8.9 \mu \mathrm{m}$, (c) $8.9-9.3 \mu \mathrm{m}$, (d) $10.3-11.0 \mu \mathrm{m}$ and (e) $11.0-11.7 \mu \mathrm{m}$, for Loobs Sand (NS) sample. Results were presented for solar plane. 


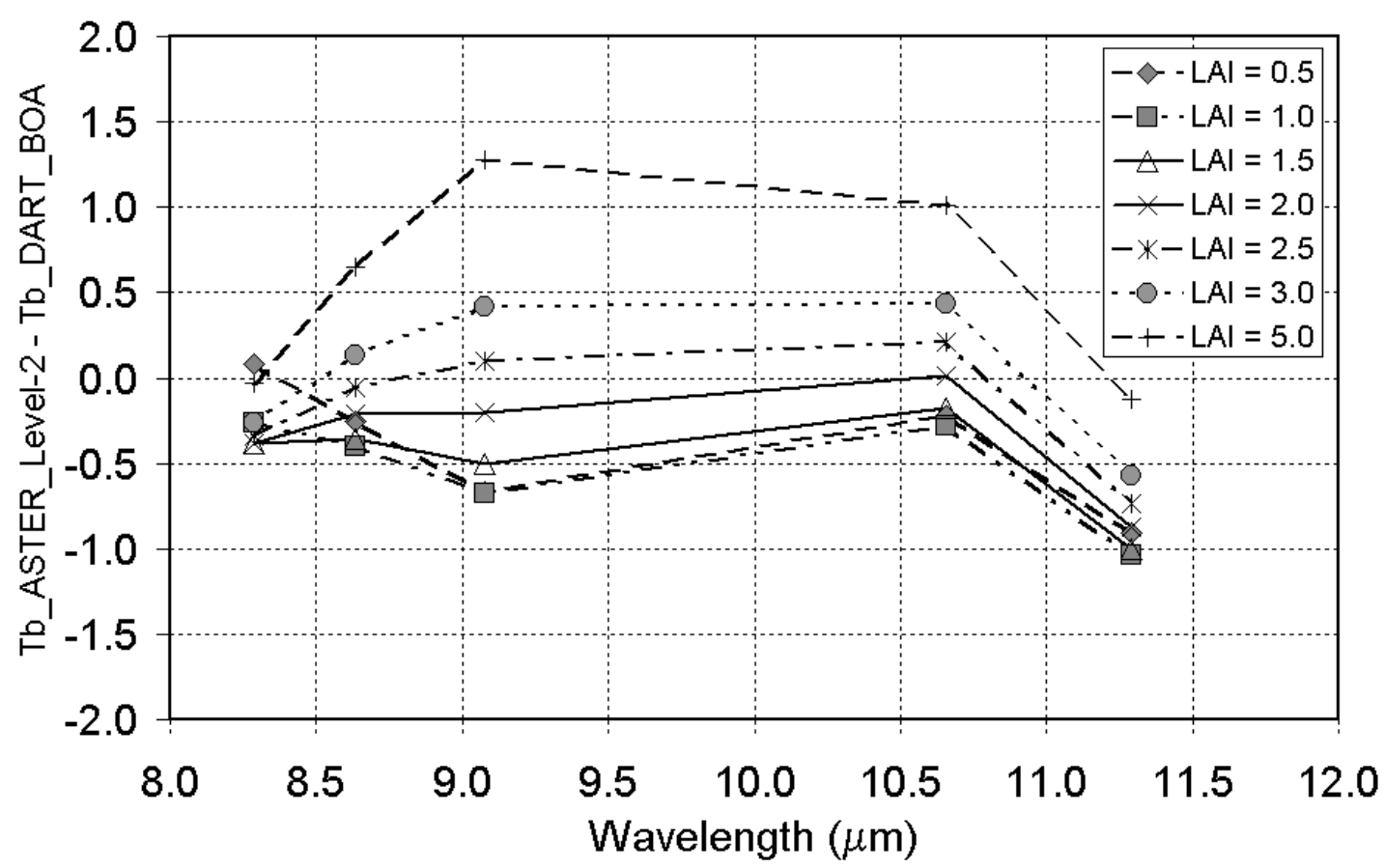

(a)

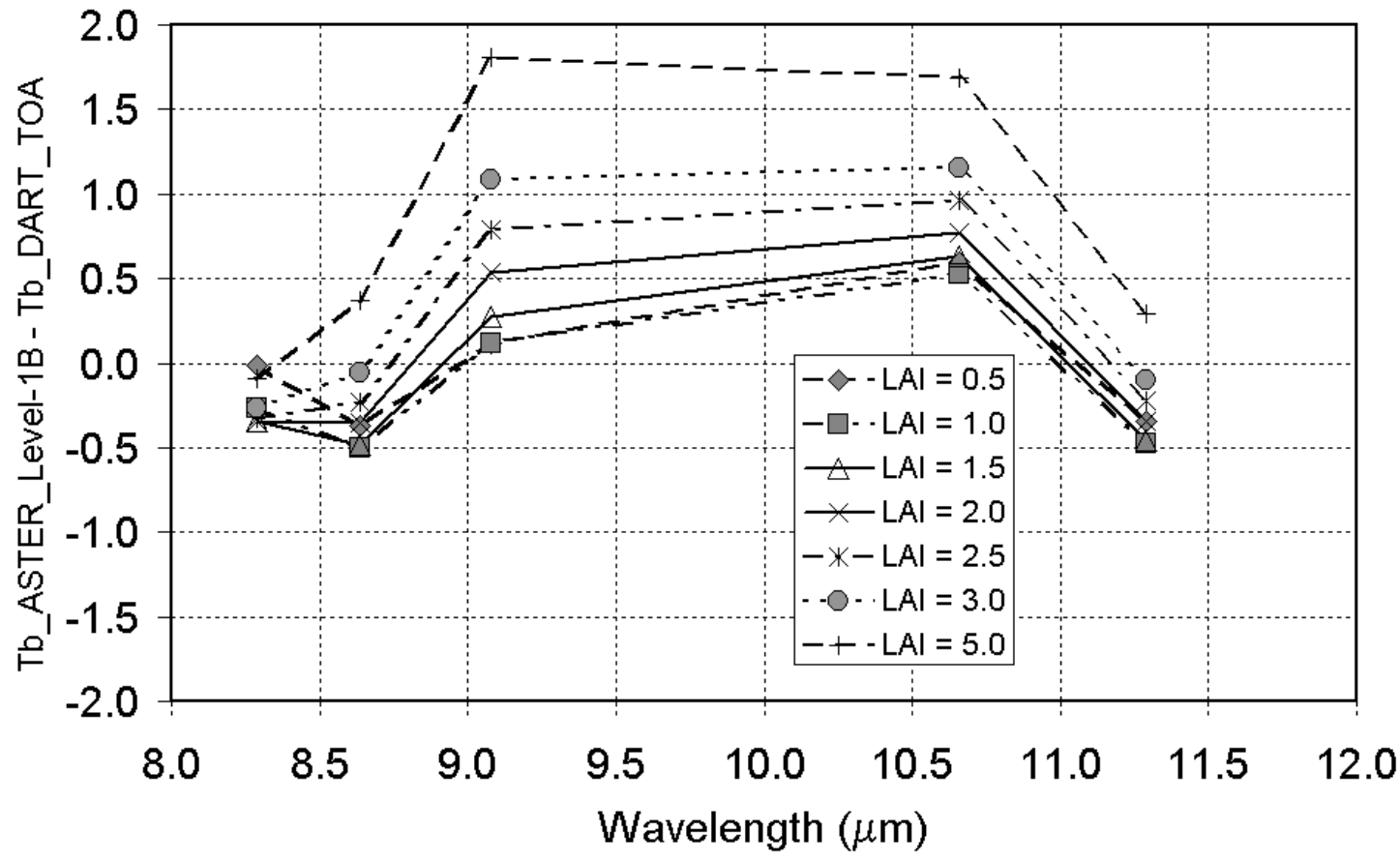

(b)

Figure 9. Brightness temperature $(\mathrm{Tb})$ differences $(\mathrm{K})$ between DART simulation and ASTER products using several LAI values. Results are presented for BOA (a) and TOA (b) levels. 


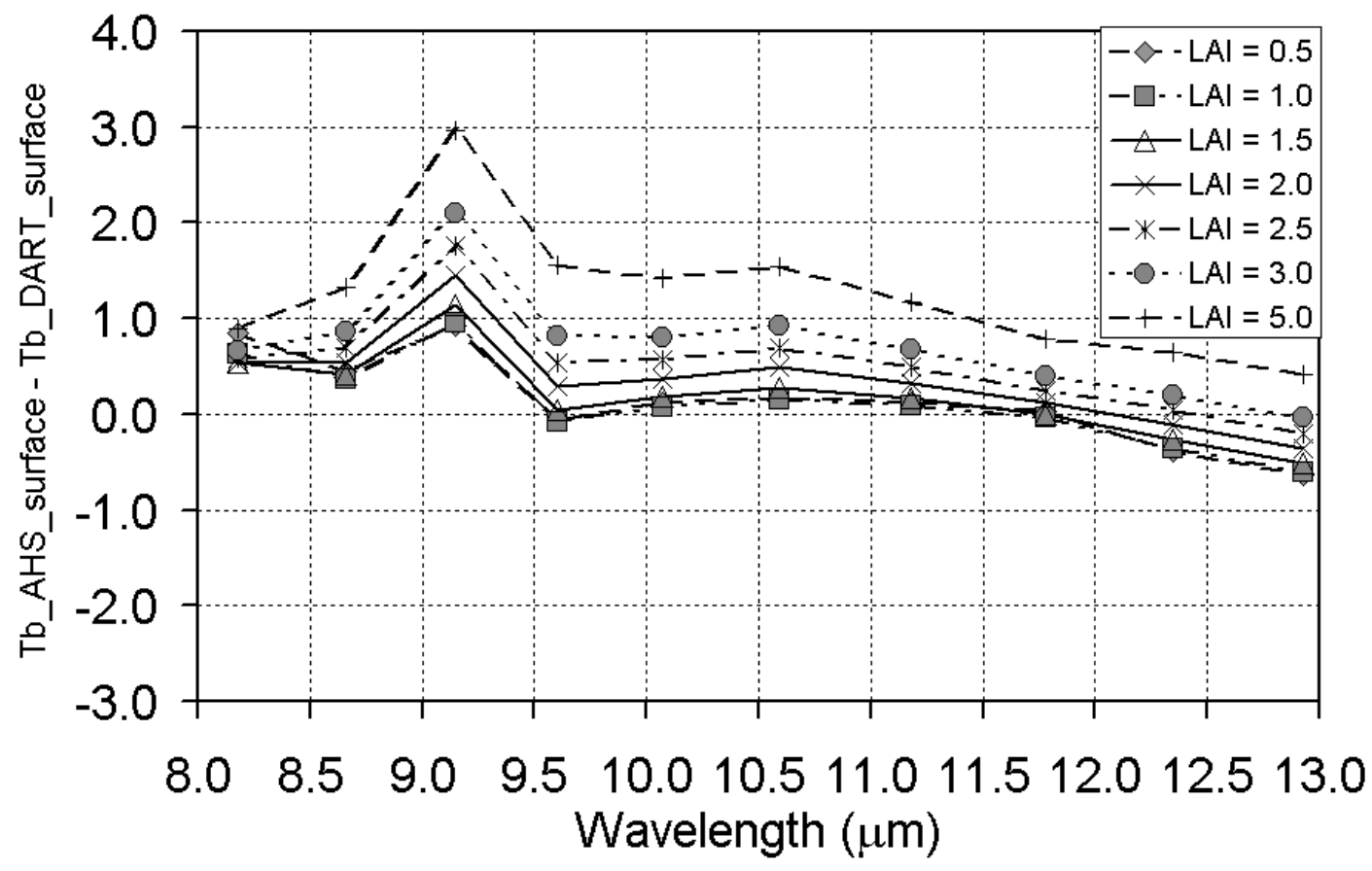

(a)

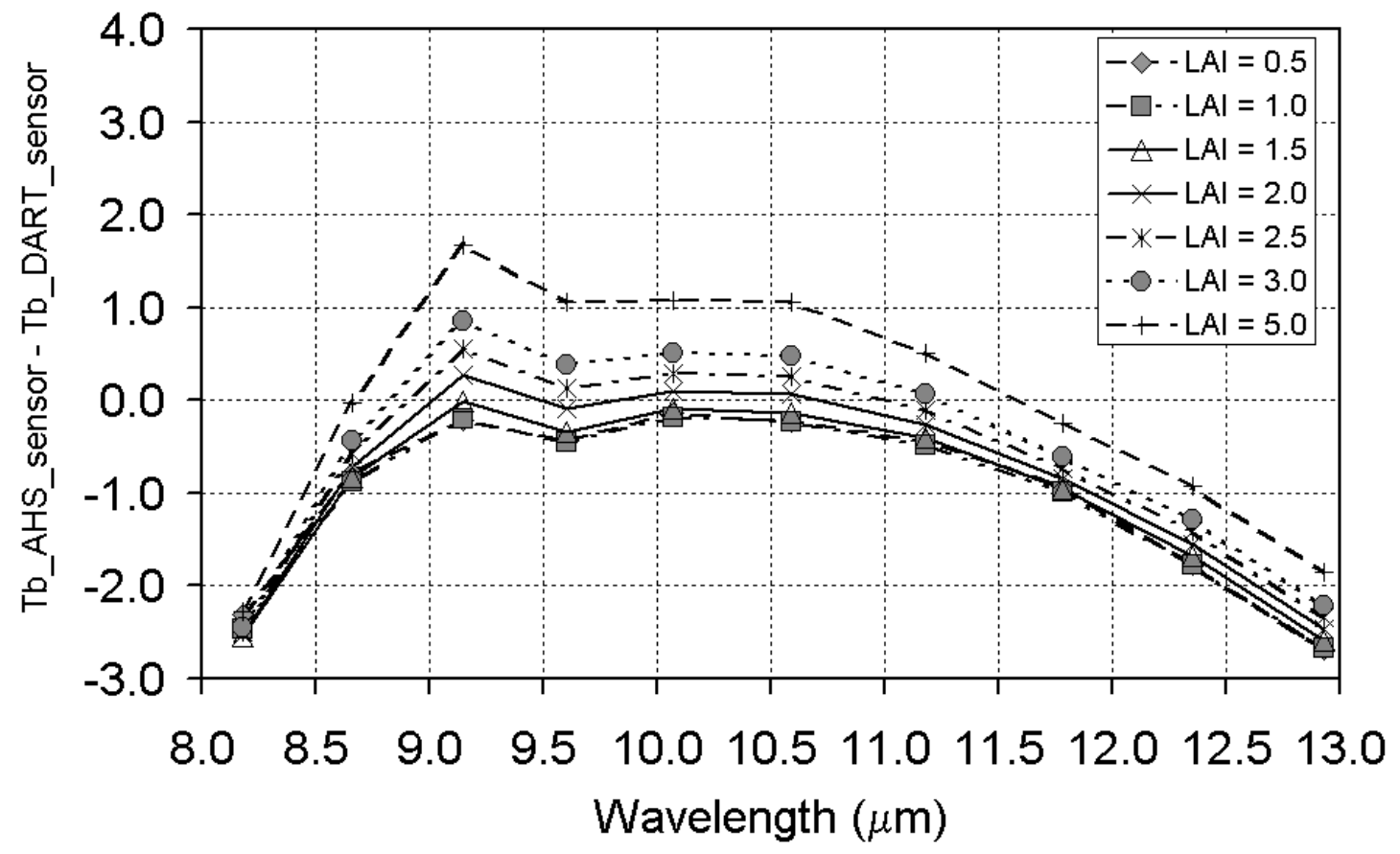

(b)

Figure 10. Brightness temperature $(\mathrm{Tb})$ differences $(\mathrm{K})$ between DART simulation and AHS imagery using several LAI values. Results are presented atsurface (a) and sensor (b) levels. 


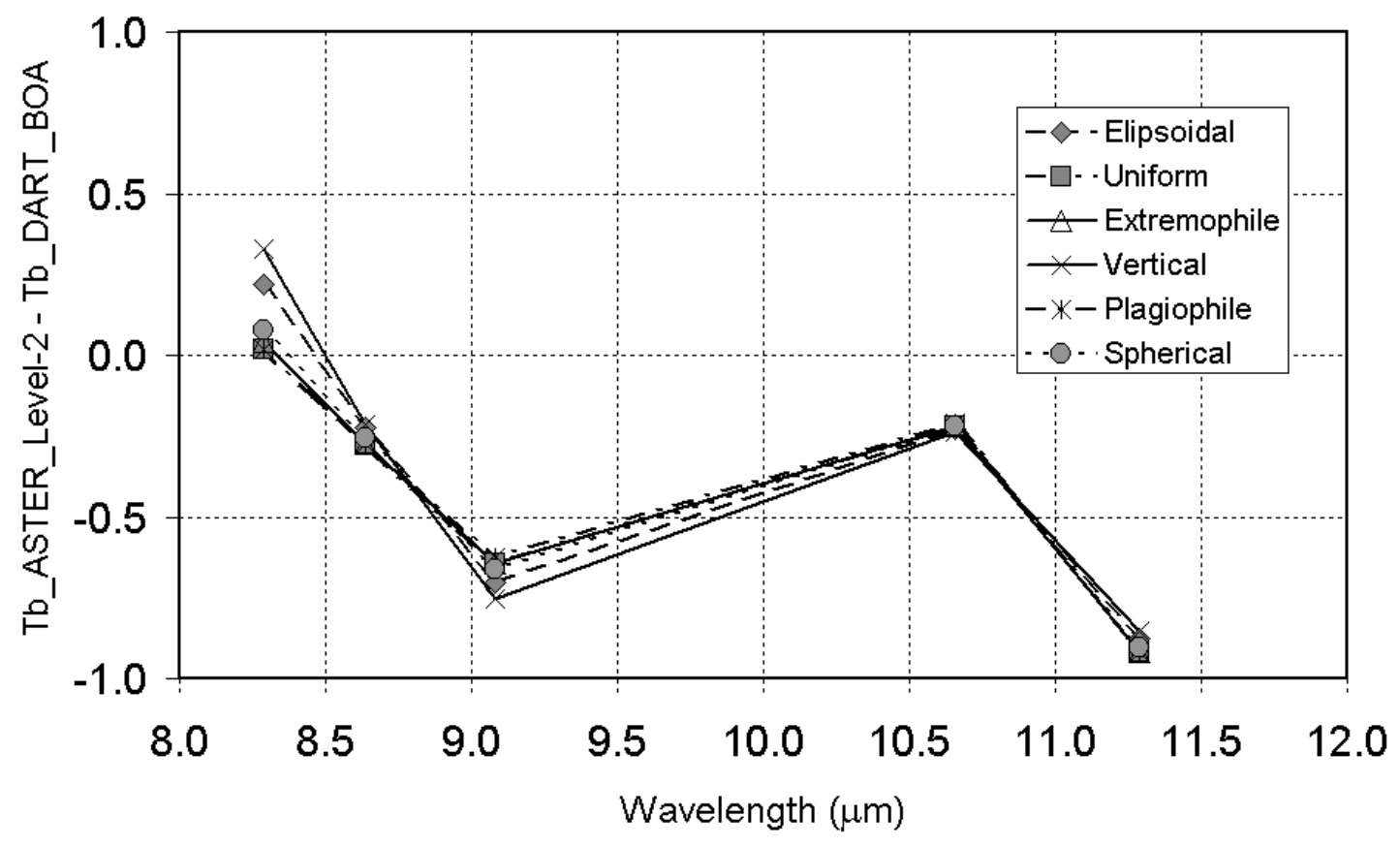

(a)

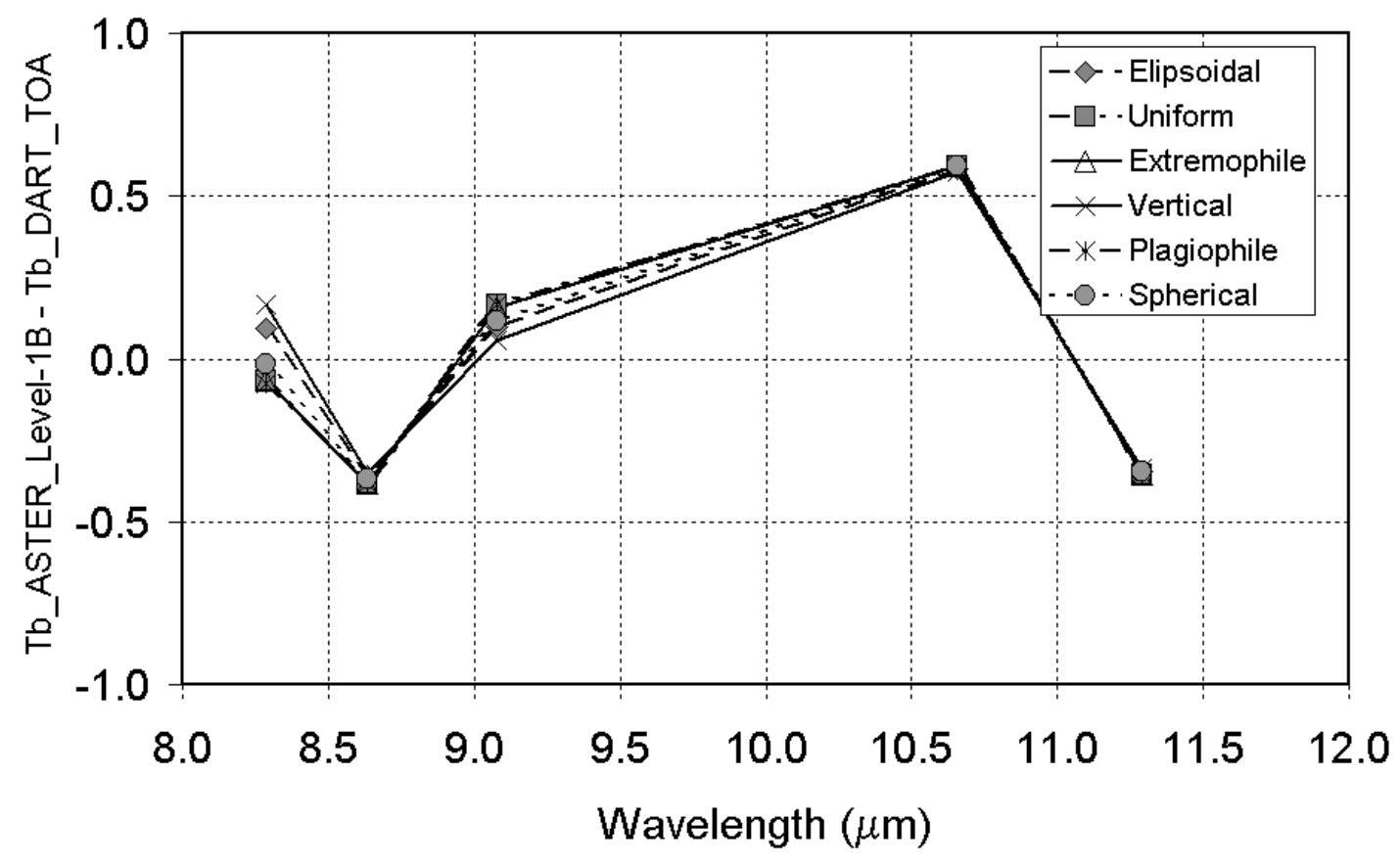

(b)

Figure 11. Brightness temperature $(\mathrm{Tb})$ differences $(\mathrm{K})$ between DART simulation and AHS imagery using several LAD values. Results are presented for BOA (a) and TOA (b) levels. 


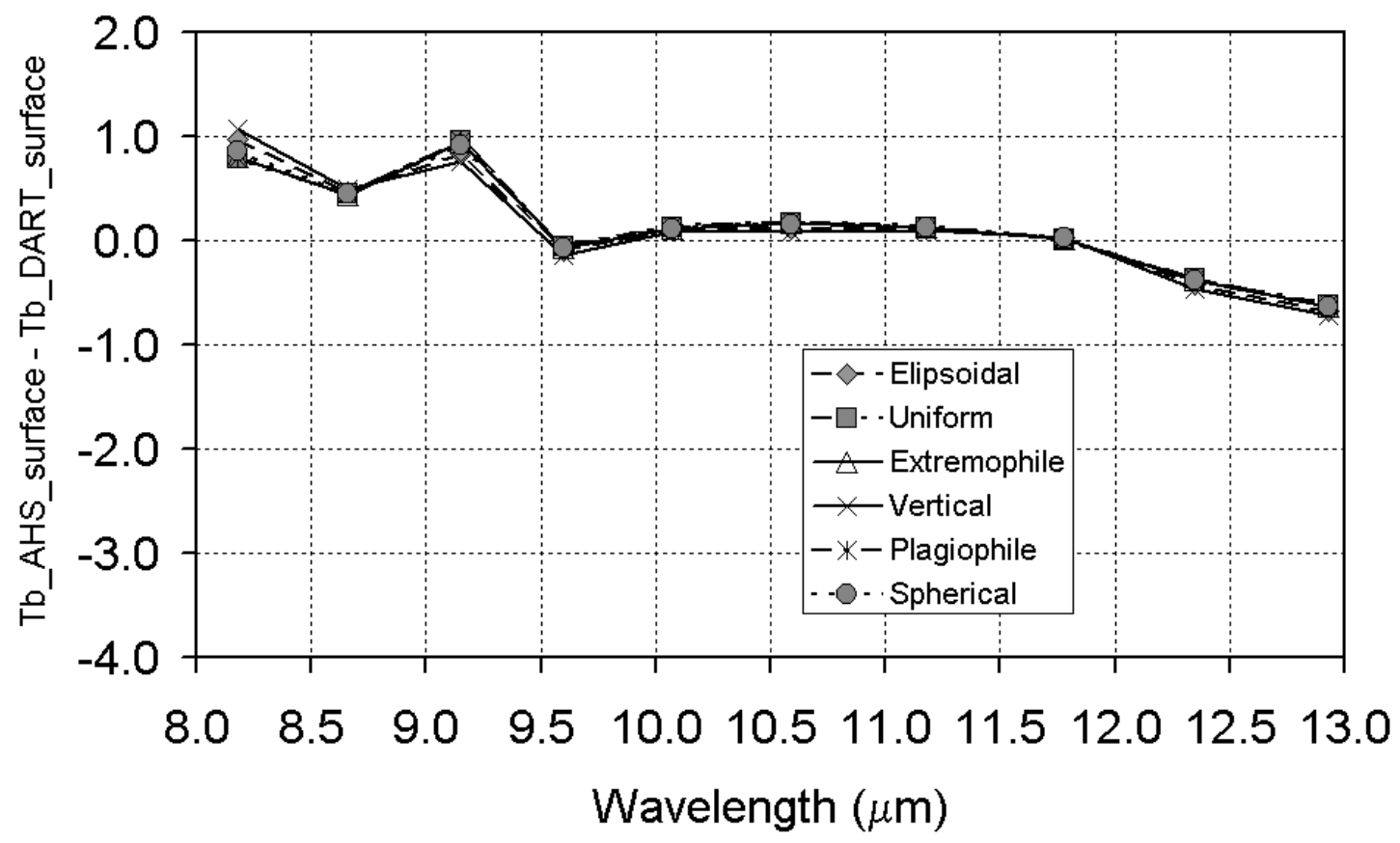

(a)

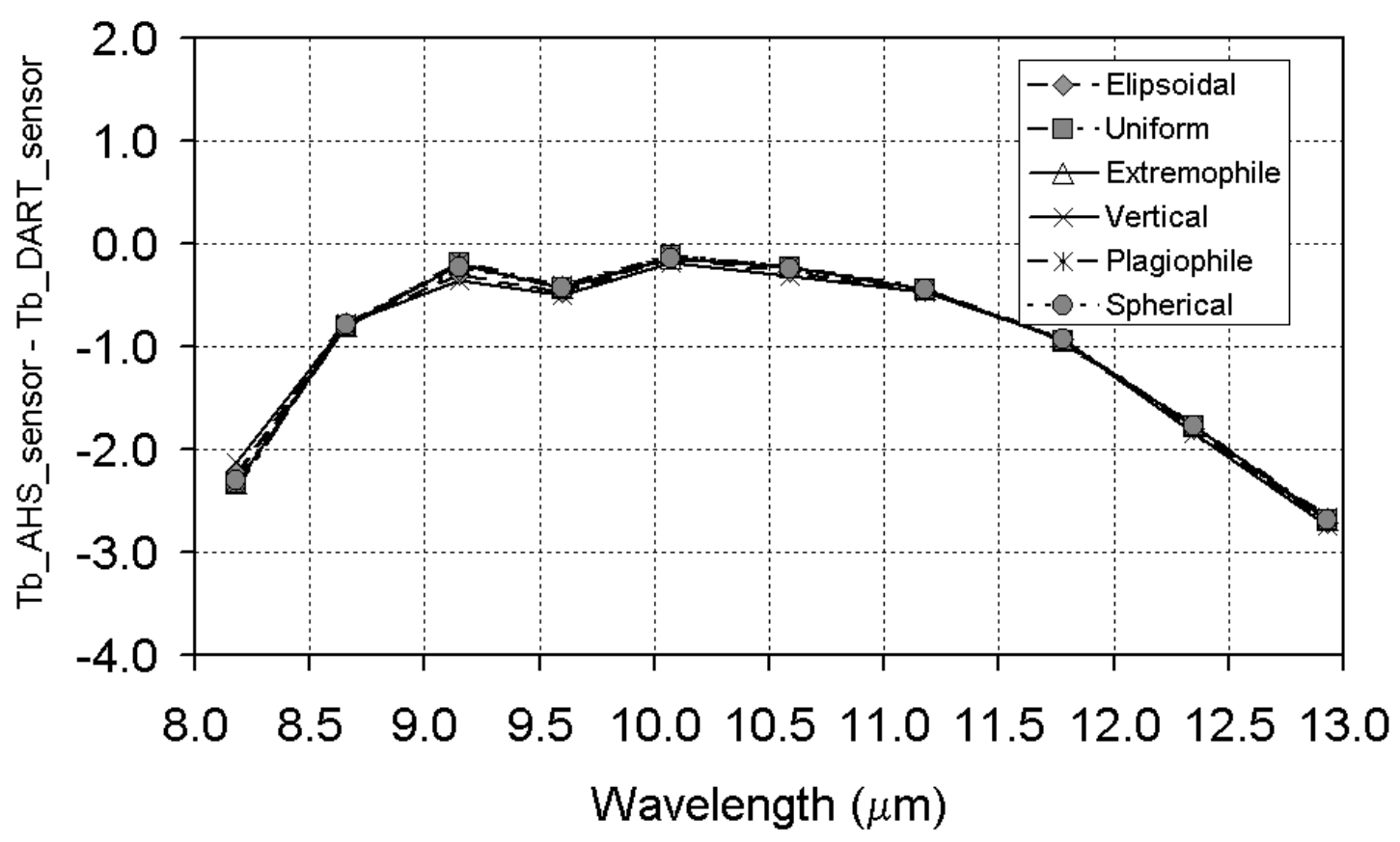

(b)

Figure 12. Brightness temperature $(\mathrm{Tb})$ differences $(\mathrm{K})$ between DART simulation and AHS imagery using several LAD values. Results are presented at- surface (a) and sensor (b) levels. 


\section{LIST OF TABLES}

Table 1. AHS Thermal bands

\begin{tabular}{ccc}
\hline \multirow{2}{*}{ Band } & $\begin{array}{c}\text { Full Width Half Maximun } \\
\text { FWHM }(\mu \mathrm{m})\end{array}$ & Effective Wavelenght $(\mu \mathrm{m})$ \\
\hline 71 & $7.95-8.42$ & 8.18 \\
72 & $8.45-8.84$ & 8.66 \\
73 & $8.94-9.35$ & 9.15 \\
74 & $9.38-9.81$ & 9.6 \\
75 & $9.85-10.27$ & 10.07 \\
76 & $10.31-10.86$ & 10.59 \\
77 & $10.89-11.45$ & 11.18 \\
78 & $11.49-12.05$ & 11.78 \\
79 & $12.09-12.57$ & 12.35 \\
80 & $12.65-13.14$ & 12.93 \\
\hline
\end{tabular}

Table 2. Input data for DART simulation according to SPARC 2004 field campaign.

\begin{tabular}{|c|c|c|}
\hline & \multicolumn{2}{|c|}{ Input parameters for DART simulation } \\
\hline & Green Grass & Bare soil \\
\hline \multicolumn{3}{|l|}{ Scene Configuration } \\
\hline Solar azimuth angle $\left(^{\circ}\right)$ & 319.57 & 319.57 \\
\hline Solar zenith angle $\left(^{\circ}\right)$ & 158.18 & 158.18 \\
\hline Directions Number & 95 & 95 \\
\hline Scene Size (m) & $90 \times 90$ & $90 \times 90$ \\
\hline Cell Size $X, Y, Z(m)$ & $3 \times 3 \times 0.3$ & $3 \times 3 \times 0.1$ \\
\hline \multicolumn{3}{|l|}{ Surface Temperature (K) } \\
\hline Minimum & 309.6 & 325.6 \\
\hline Maximum & 312.6 & 328 \\
\hline \multicolumn{3}{|l|}{ Emissivity (ASTER Bands) } \\
\hline Band $10(8,1-8,5 \mu \mathrm{m})$ & 0.989 & 0.989 \\
\hline Band $11(8,5-8,9 \mu \mathrm{m})$ & 0.983 & 0.983 \\
\hline Band $12(8,9-9,3 \mu \mathrm{m})$ & 0.969 & 0.969 \\
\hline Band $13(10,3-11,0 \mu \mathrm{m})$ & 0.981 & 0.981 \\
\hline Band $14(11,0-11,7 \mu \mathrm{m})$ & 0.987 & 0.987 \\
\hline \multicolumn{3}{|l|}{ Structural parameters } \\
\hline Height (m) & $0.3 \pm 0.1$ & ----- \\
\hline$L A I$ & $0.5 \pm 0.1$ & ----- \\
\hline$L A D$ & Spherical & ----- \\
\hline \multicolumn{3}{|l|}{ Atmospheric Model } \\
\hline Visibility & $\begin{array}{l}\text { Rural } \\
(23 \mathrm{~km})\end{array}$ & $\begin{array}{l}\text { Rural } \\
(23 \mathrm{~km})\end{array}$ \\
\hline Ozone Model & Midlatitude summer & Midlatitude summer \\
\hline Aerosol Model & Midlatitude summer & Midlatitude summer \\
\hline Temperature Model & $\begin{array}{c}\text { Radiosonde in-situ } \\
\text { to } 25 \mathrm{~km} . \\
+\end{array}$ & $\begin{array}{c}\text { Radiosonde in-situ to } \\
25 \mathrm{~km} . \\
+\end{array}$ \\
\hline
\end{tabular}


Table 3. Input data for DART simulation according to SEN2FLEX 2005 field campaign.

\begin{tabular}{|c|c|c|}
\hline & \multicolumn{2}{|c|}{ Input parameters for DART simulation } \\
\hline & Green Grass & Bare Soil \\
\hline \multicolumn{3}{|l|}{ Scene Configuration } \\
\hline Solar azimuth angle $\left(^{\circ}\right)$ & 318.05 & 318.05 \\
\hline Solar zenith angle $\left(^{\circ}\right)$ & 159.01 & 159.01 \\
\hline Directions Number & 95 & 95 \\
\hline Scene Size (m) & $60 \times 60$ & $60 \times 60$ \\
\hline Cell Size $X, Y, Z(m)$ & $3 \times 3 \times 0.3$ & $3 \times 3 \times 0.1$ \\
\hline \multicolumn{3}{|l|}{ Surface Temperature (K) } \\
\hline Minimum & 329.3 & 309.2 \\
\hline Maximum & 331.5 & 311.1 \\
\hline \multicolumn{3}{|l|}{ Emissivity (AHS bands) } \\
\hline Band $71(7.95-8.42 \mu \mathrm{m})$ & 0.990 & 0.945 \\
\hline Band $72(8.45-8.84 \mu \mathrm{m})$ & 0.981 & 0.967 \\
\hline Band $73(8.94-9.35 \mu \mathrm{m})$ & 0.969 & 0.971 \\
\hline Band $74(9.38-9.81 \mu \mathrm{m})$ & 0.975 & 0.969 \\
\hline Band $75(9.85-10.27 \mu \mathrm{m})$ & 0.980 & 0.974 \\
\hline Band $76(10.31-10.86 \mu \mathrm{m})$ & 0.981 & 0.979 \\
\hline Band $77(10.89-11.45 \mu \mathrm{m})$ & 0.985 & 0.980 \\
\hline Band $78(11.49-12.05 \mu \mathrm{m})$ & 0.989 & 0.981 \\
\hline Band $79(12.09-12.57 \mu \mathrm{m})$ & 0.988 & 0.985 \\
\hline Band $80(12.65-13.14 \mu \mathrm{m})$ & 0.989 & 0.985 \\
\hline \multicolumn{3}{|l|}{ Structural parameters } \\
\hline Height (m) & $0.3 \pm 0.1$ & ----- \\
\hline$L A I$ & $0.6 \pm 0.1$ & ----- \\
\hline$L A D$ & Spherical & ----- \\
\hline \multicolumn{3}{|l|}{ Atmospheric Model } \\
\hline Visibility & $\begin{array}{c}\text { Rural } \\
(23 \mathrm{~km})\end{array}$ & $\begin{array}{c}\text { Rural } \\
(23 \mathrm{~km})\end{array}$ \\
\hline Ozone Model & Midlatitude summer & Midlatitude summer \\
\hline \multirow[t]{2}{*}{ Aerosol Model } & Midlatitude summer & Midlatitude summer \\
\hline & $\begin{array}{l}\text { Radiosonde in- } \\
\text { situ to } 25 \mathrm{~km} \text {. }\end{array}$ & $\begin{array}{l}\text { Radiosonde in-situ to } \\
25 \mathrm{~km} .\end{array}$ \\
\hline \multirow[t]{2}{*}{ Temperature Model } & + & + \\
\hline & $\begin{array}{c}\text { Midlatitude summer } \\
\text { to TOA }\end{array}$ & $\begin{array}{c}\text { Midlatitude summer to } \\
\text { TOA }\end{array}$ \\
\hline $\begin{array}{l}\text { Water Vapor content } \\
\left(\mathrm{gr} \mathrm{cm}^{-2}\right)\end{array}$ & 1.67 & 1.67 \\
\hline
\end{tabular}


Table 4. Summary of DART input parameters for angular measurement comparisons. The letter $\mathrm{D}$ and $\mathrm{N}$ belong to Day and Night respectively.

\begin{tabular}{|c|c|c|c|}
\hline & \multicolumn{3}{|c|}{$\begin{array}{l}\text { Input parameter for ground cover } \\
\text { simulation by DART model }\end{array}$} \\
\hline & Bare soil & Green Grass & Sand \\
\hline \multicolumn{4}{|l|}{ Scene Configuration } \\
\hline Solar azimuth angle $\left({ }^{\circ}\right)$ & $150 / 180$ & $150 / 180$ & 150/------ \\
\hline Solar zenith angle $\left(^{\circ}\right)$ & $45 / 45$ & $45 / 45$ & 45/------ \\
\hline Directions Number & 95 & 95 & 95 \\
\hline Scene Size (m) & $10 \times 10$ & $10 \times 10$ & $10 \times 10$ \\
\hline Cell Size X, Y, Z (m) & $\begin{array}{c}0.5 \times 0.5 \times \\
0.5\end{array}$ & $\begin{array}{c}0.5 \times 0.5 \times \\
0.5\end{array}$ & $\begin{array}{c}0.5 \times 0.5 \times \\
0.5\end{array}$ \\
\hline
\end{tabular}

\section{Surface Temperature (K)}

Minimum

Maximum

\section{Emissivity (ASTER - CIMEL Bands)}

Band $10(8,1-8,5 \mu \mathrm{m})$

Band $11(8,5-8,9 \mu \mathrm{m})$

0.949

0.989

0.736

Band $12(8,9-9,3 \mu \mathrm{m})$

0.968

0.983

0.752

Band 13 (10,3 - 11,0 $\mu \mathrm{m})$

0.972

0.969

0.737

0.979

0.981

0.956

Band $14(11,0$ - 11,7 $\mu \mathrm{m})$

0.978

0.987

0.968

Structural parameters

\begin{tabular}{cccc} 
Height $(m)$ & ---- & $0.5 \pm 0.1$ & ----- \\
LAI & ---- & $0.5 \pm 0.2$ & ----- \\
LAD & ---- & Spherical & ---- \\
\hline Atmospheric Model & & & \\
Visibility & Rural & Rural & Rural \\
Ozone Model & $(23 \mathrm{~km})$ & $(23 \mathrm{~km})$ & $(23 \mathrm{~km})$ \\
Aerosol Model & Midlatitude & Midlatitude & Midlatitude \\
summer & summer & summer
\end{tabular}




$\begin{array}{ccc} & \begin{array}{c}\text { Radiosonde } \\ \text { in-situ to } 25 \\ \mathrm{~km} .\end{array} & \begin{array}{c}\text { Radiosonde } \\ \text { in-situ to } 25\end{array} \\ \text { Temperature Model } & + & + \\ \text { Midlatitude } & \text { Midlatitude } \\ \text { summer to } & \text { summer to } \\ \text { TOA } & \text { TOA }\end{array}$

Water Vapor $\left(\mathrm{gr} \mathrm{cm}^{-2}\right)$

1.7

1.7

Table 5. Bias, $\sigma$ and RMSE values for brightness temperature between ASTER, AHS and DART simulation. Results are showed for bare soil and green grass at two atmospheric levels.

\begin{tabular}{ccccc} 
& & Bias & $\sigma$ & RMSE \\
\hline \multirow{4}{*}{ Bare Soil } & ASTER Level - 1B & -4.16 & 0.68 & 4.21 \\
& ASTER Level - 2 & -4.51 & 0.70 & 4.56 \\
& AHS surface & 0.47 & 0.42 & 0.63 \\
Green Grass & AHS sensor & -1.73 & 1.51 & 2.30 \\
\hline \multirow{5}{*}{ ASTER Level - 1B } & -0.003 & 0.39 & 0.39 \\
& ASTER Level - 2 & -0.39 & 0.39 & 0.55 \\
& AHS surface & 0.16 & 0.49 & 0.51 \\
& AHS sensor & -0.99 & 0.93 & 1.36 \\
\hline
\end{tabular}


Table 6. Bias, $\sigma$ and RMSE values for the angular brightness temperature comparison between DART and in-situ measurements for GG, BS and NS plots. Results for mono and multispectral simulations are also shown.

\begin{tabular}{|c|c|c|c|c|c|c|c|c|c|}
\hline & & \\
\hline & & $8.1-8.5 \mu \mathrm{m}$ & $8.5-8.9 \mu \mathrm{m}$ & $8.9-9.3 \mu \mathrm{m}$ & $10.3-11.0 \mu \mathrm{m}$ & $11.0-11.7 \mu \mathrm{m}$ & BIAS & $\sigma$ & RMSE \\
\hline \multirow{4}{*}{ Daytime } & DART mono - In situ for GG & -1.05 & -0.35 & -0.14 & -0.08 & -0.26 & -0.37 & 0.59 & 0.70 \\
\hline & DART multi - In situ for GG & 0.05 & 0.43 & 0.56 & 0.73 & 0.63 & 0.48 & 0.55 & 0.73 \\
\hline & DART mono - In situ for BS & -0.73 & -0.44 & -0.38 & -0.33 & -0.43 & -0.46 & 0.32 & 0.56 \\
\hline & DART multi - In situ for BS & -0.96 & -0.38 & 0.69 & -0.13 & -0.25 & -0.21 & 0.60 & 0.63 \\
\hline \multirow{6}{*}{ Nighttime } & DART mono - In situ for GG & -1.71 & -0.12 & -0.04 & 0.32 & -0.06 & -0.32 & 0.73 & 0.80 \\
\hline & DART multi - In situ for GG & -0.86 & 0.51 & 0.54 & 1.00 & 0.69 & 0.38 & 0.68 & 0.77 \\
\hline & DART mono - In situ for BS & -1.86 & -0.02 & 0.23 & 0.62 & 0.20 & -0.16 & 0.90 & 0.91 \\
\hline & DART multi - In situ for BS & -1.86 & 0.08 & 0.38 & 0.77 & 0.34 & -0.06 & 0.98 & 0.98 \\
\hline & DART mono - In situ for NS & 6.67 & 4.88 & 3.42 & 1.62 & 1.56 & 3.63 & 2.00 & 4.15 \\
\hline & DART multi - In situ for NS & 3.00 & 2.41 & 1.19 & 1.39 & 1.34 & 1.87 & 0.79 & 2.02 \\
\hline
\end{tabular}

